\title{
PROBABILISTIC AND DETERMINISTIC LOWER-BOUND DESIGN BENCHMARKS FOR CYLINDRICAL SHELLS UNDER AXIAL COMPRESSION
}

\author{
H.N.R. Wagner ${ }^{\mathrm{a}, \mathrm{b}}$, C. Hühne $\mathrm{e}^{\mathrm{a}, \mathrm{c}}$ and I. Elishakoff ${ }^{\mathrm{d}}$ \\ ${ }^{a}$ Technische Universität Braunschweig, Institute of Adaptronics and Function Integration, Langer \\ Kamp 6, 38106 Braunschweig, Germany \\ ro.wagner@tu-braunschweig.de

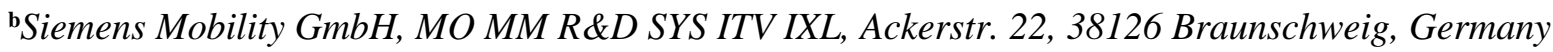 \\ ${ }^{\mathrm{c}}$ German Aerospace Center (DLR), Institute for Composite Structures and Adaptive Systems, \\ Lilienthalplatz 7, 38108 Braunschweig, Germany \\ christian.huehne@dlr.de \\ ${ }^{d}$ Department of Ocean and Mechanical Engineering, Florida Atlantic University, Boca Raton, FL, USA \\ elishako@fau.edu
}

Keywords: Shell buckling, probabilistic design, knockdown factor, geometric imperfection, reduced stiffness analysis

\begin{abstract}
This article contains examples to demonstrate the use of different design concepts for cylindrical shells under axial compression. The examples are based on shells which were manufactured according to electroplating, machining, welding (isotropic cylinders) and prepreg hand layup on a mandrel (composite cylinders). Three of the four shell series are characterized by pure elastic buckling and one shell series buckled in the elastic-plastic region. All relevant data for the numerical analysis are described in the article and summarized in the Elsevier repository of this article (geometry, material, measured imperfection data and Python-ABAQUS scripts).

The design concepts are based on the geometric imperfection signatures, probabilistic and deterministic lower-bound methods. The design concepts are representative for the development of design approaches for imperfection sensitive shells from the early 1980 to the late 2010 and are validated with experimental data. Recently developed design lower-bound curves for axially loaded cylinders are presented and compared with currently used design criteria like the Eurocode EN 1993-1-6 and the NASA SP-8007. The results of this article show that the design of imperfection sensitive cylinders has been significantly improved in the last 30 years.
\end{abstract}




\section{Abbreviations and glossary}

$\begin{array}{cl}\text { Exp. } & \text { Experiment } \\ \text { F } & \text { Axial Force } \\ \text { FC } & \text { Fourier Coefficients } \\ \text { FOSM } & \text { First-Order Second-Moment Method } \\ \text { GNA } & \text { Geometrically nonlinear analysis } \\ \text { GNIA } & \text { Geometrically nonlinear analysis with imperfections } \\ \text { KDF } & \text { Knockdown factor } \\ \text { L } & \text { Free Length of a cylinder } \\ \text { LBA } & \text { Linear Bifurcation Analysis } \\ \text { LRSM } & \text { Localized Reduced Stiffness Method } \\ \text { MGI } & \text { Measured geometric imperfections } \\ \text { N } & \text { Buckling load } \\ N_{\text {imp }} & \text { Buckling load of an imperfect shell } \\ N_{\text {per }} & \text { Buckling load of a perfect shell } \\ \text { R } & \text { Radius of a cylinder } \\ \text { RRD } & \text { Reference Resistance Design } \\ \text { RSM } & \text { Reduced Stiffness Method } \\ \text { SBPA } & \text { Single Boundary Perturbation Approach } \\ \text { t } & \text { Wall thickness of a cylinder } \\ \text { TH } & \text { Threshold } \\ \text { u } & \text { axial displacement } \\ \text { Z } & \text { Batdorf Parameter } \\ \text { P } & \text { knockdown factor in general } \\ \end{array}$




\section{Introduction}

Thin-walled structures like cylindrical shells tend to buckle under axial compression, which means that large deformations in the shell surface perpendicular to the loading direction occur. This buckling pattern propagates over a large proportion of the shell surface and occurs without prior notice. The buckling phenomenon is accompanied by a significant loss of the load carrying capability of the shell. Buckling is therefore one of the primary design drivers in aerospace and civil engineering shell structures.

Within this article, the maximum load carrying capability of thin-walled cylindrical shells under axial compression [1] is defined as the buckling load $N_{p e r}$ according to equation (1):

$$
N_{\text {per }}=\frac{2 \cdot \pi \cdot E \cdot t^{2}}{\sqrt{3\left(1-v^{2}\right)}}
$$

This equation depends on the elasticity modulus $\mathrm{E}$, the Poisson ratio $v$, the wall thickness $t$ and is independent from the cylinder radius $\mathrm{R}$ as well as the cylinder length $\mathrm{L}$.

If plastic buckling is relevant, the buckling load (squash load [1]) depends on the yield strength $\mathrm{Y}$ and can be determined with equation (2):

$$
N_{\text {squash }}=2 \cdot \pi \cdot E \cdot R \cdot t \cdot Y
$$

A large amount of cylinders was tested at the beginning of the $20^{\text {th }}$ century in order to understand shell buckling under axial compression. The buckling results are commonly represented by means of so called knockdown factors (KDFs) which are defined as the ratio of the experimental buckling load $\mathrm{N}_{\text {exp }}$ to the theoretical perfect buckling load $\mathrm{N}_{\text {per }}$, see equation (3).

$$
\rho_{\text {exp }}=\frac{N_{\text {exp }}}{N_{\text {per }}}
$$

In Fig. 1 knockdown factors derived from a large number of tests are shown versus the radiusto-thickness ratio $(\mathrm{R} / \mathrm{t}$ - slenderness).

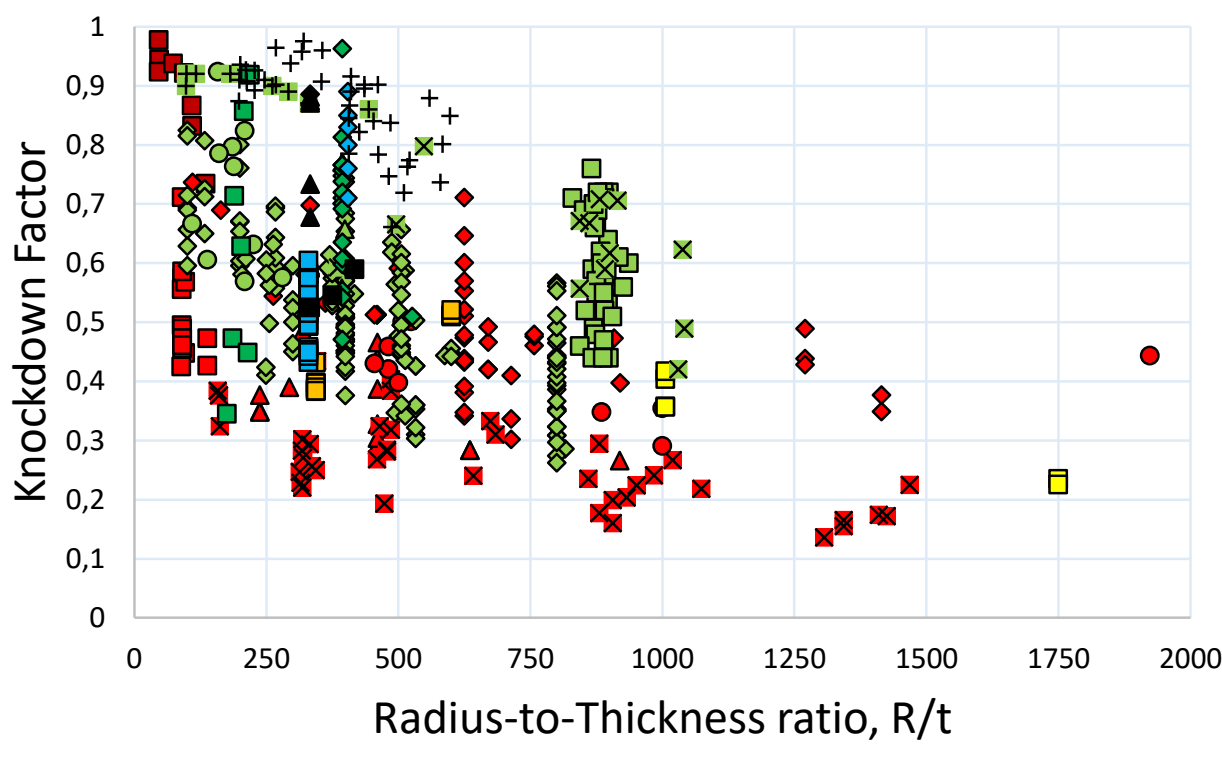

口 Robertson [1928]

口Flügge [1932]

$\diamond$ Lundquist [1933]

$\Delta$ Bridget [1934]

x Donnel [1934]

- Ballerstedt [1936]

口Bruhn [1945]

口Harris [1957]

口Babcock [1963]

$\diamond$ Weingarten [1965]

$\Delta$ Almroth [1966]

X Arbocz [1968]

o Muggeridge [1969]

+ Tennyson [1969]

口Hutchinson [1971]

๑ Esslinger [1972]

口 Verduyn [1982]

Yamaki [1984]

+ Krishnakumar [1991]

- Jiao [2018]

- Wang [2018]

A Wang [2019]

Fig. 1: Distribution of 517 experimental results for isotropic cylindrical shells under axial compression for different R/t ratios after [2], [3], [4], [5], [6] [7], [8], [9], [10], [11], [12] and [13] 
The empirical data collection shows that there is a significant deviation between buckling theory and corresponding experimental data. The KDFs range mainly from about $0.4 \ldots 1$ and are in some cases even below 0.2. Some of the illustrated tests are affected by plasticity, weld land failure, material failure, poor load introduction and poor boundary support [14]. In addition, most of the test data are poorly documented [1].

Although manufacturing and testing of shells has been significantly improved, there are still significant deviations between predicted and experimental determined buckling load. The results illustrated in Fig. 2 are based on shell buckling experiments from 1975 - 2016 for composite cylinders and the KDFs are in some cases below 0.5 . The corresponding data collection is given by Takano [15].

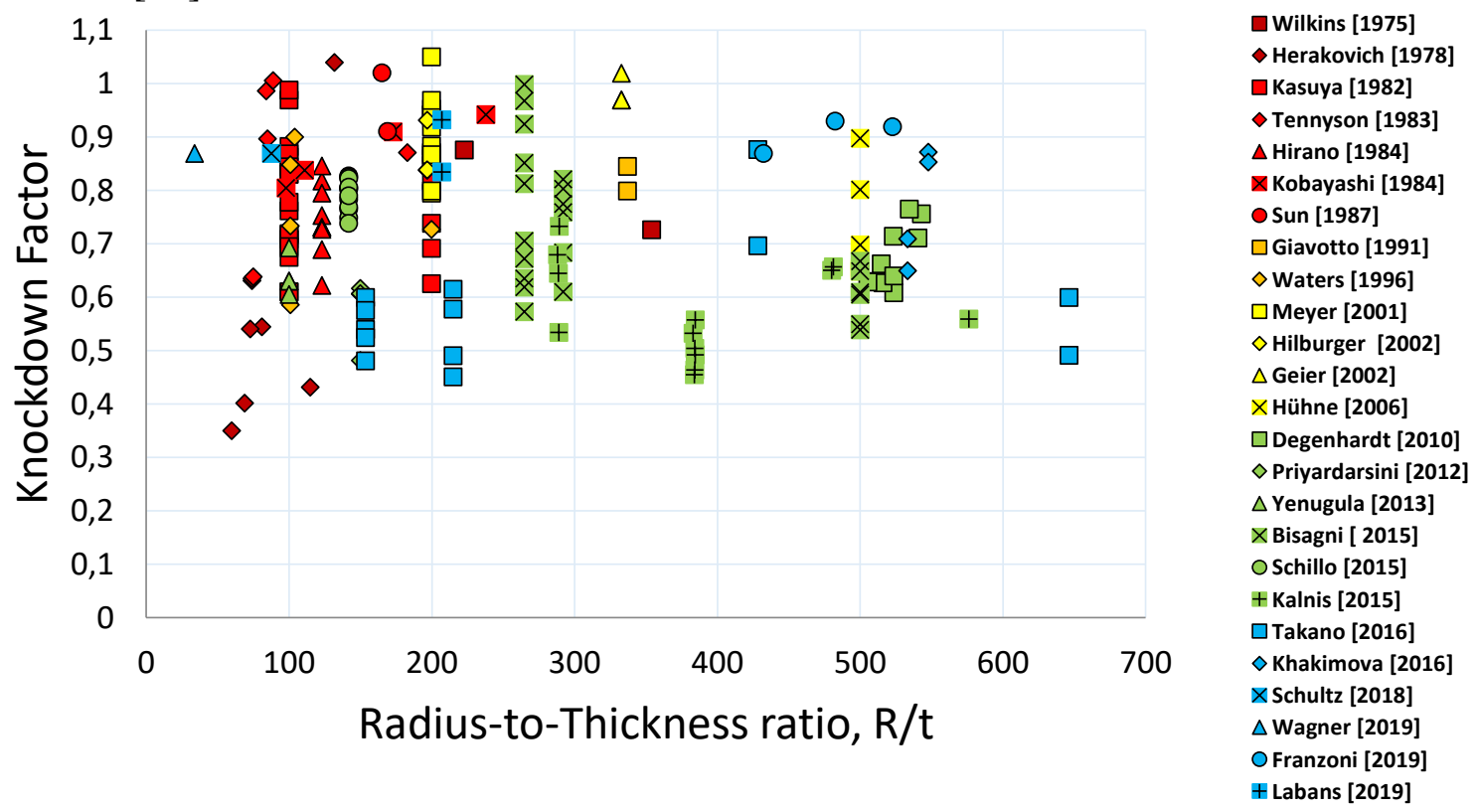

Fig. 2: Distribution of 143 experimental results for composite cylindrical shells under axial compression for different R/t ratios after [15], [16], [17] and [18]

A main cause for the large discrepancy between buckling theory and experiment are shape deviations from the ideal cylinder geometry, namely geometric imperfections [19], [20]. The geometric imperfections have been at first described by expansions in terms of buckling eigenmodes and the corresponding amplitudes were regarded as random variables [21].

A more realistic approach was proposed by Arbocz [22] who used real measured geometric imperfection of cylindrical shells. In this case, the geometric imperfections are described by means of a double Fourier series and the Fourier coefficients are the random variables of the probabilistic analysis. Arbocz and Abramovich [23] showed that double Fourier series are well suited to describe realistic geometric imperfections.

Alternative methods to represent realistic geometric imperfections are the multimode approach [24], the spectral representation [25] and the circumferential phase shift representation [26]. However, nearly all of the available geometric imperfection signatures are represented by the Fourier-series [27] and are mostly available for isotropic cylinders. Geometric imperfection measurements for composite cylinders were for example performed by Starnes et al. [28], Hühne [29] and Degenhardt et al. [30]. The imperfection pattern of composite shells has the tendency of long-wave imperfection as opposed to the short-waved imperfection pattern for metallic cylindrical shells which is based on the manufacturing process [31]. Meurer provides detailed studies regarding the mode composition of geometric imperfection signatures in [32].

The shape and amplitude of geometric imperfection can be treated as being of random nature and therefore probabilistic methods were proposed by Bolotin [33] to analyze the shell buckling. 
The random nature of geometric imperfections is subject to certain probabilistic distributions, and by using probabilistic methods the probability of buckling can be characterized [34]. Broggi [35], [36] provides a rigorous description for the probabilistic analysis with geometric imperfections of composite shells.

Schillo et al. [37] used Monte Carlo (MC) methods to generate different initial geometric imperfections and determine the corresponding buckling loads. However, the Monte Carlo method might turn to be very time-consuming and therefore the semi-analytical first-order second moment (FOSM) method was used as an alternative approach by Elishakoff [38].

The computational cost for a probabilistic analysis of geometric imperfections increases significantly as the number of included Fourier coefficients is increased. Kriegesmann et al. [39] proposed using the Mahalanobis transformation in combination with FOSM which significantly reduces the computational costs. Another alternative probabilistic design procedure was proposed by Arbocz and Hilburger in [40]. The geometric imperfection signatures are represented by only two imperfection modes and the corresponding amplitudes are defined as the root mean square of the imperfection signatures.

However, the buckling load is not only reduced by geometric imperfection [41] but also by deviation of the ideal positioning of the loading [11], [42] as well as thickness deviations [43]. In the particular case of composite shells [44] additional effects become crucial: deviation of the resin distribution or the ply-angles [45], [46]. Probabilistic analysis of cylindrical shells with multiple different imperfections (boundary conditions, loading, geometric, thickness \& material) were performed by Kriegesmann [47], Kepple [48], [49] and Meurer et al. [50]. It was demonstrated that they could approximate the corresponding stochastic distribution of the buckling load very well.

The influence of real measured geometric imperfections (MGI) on the buckling load of cylindrical shells can be assessed very well nowadays as shown for example in studies by Hilburger et al. [51] or Wang at al. [12], [52]. However, in order to study the influence of MGI, shell structures must be built, and the imperfections must be measured using optical measurement systems [17]. This process is not only time consuming but also expensive. Another problem is that most studies cover only subscale shells with a simple geometry and the corresponding results are most of the time not relevant for full scale shell structures which have complex geometries like reinforcements [53], cutouts [54], welds and stiffeners [55]. Also, the manufacturing process of small-scale shell structures like electroplating leads to different imperfections than for example the welding process of full-scale large shell structures [56].

An alternative approach to assess the imperfection sensitivity of complex shell structures is the application of perturbation or lower-bound methods [57]. Deterministic lower-bound methods are applied in order to quantify the influence of so called "worst" imperfections and were extensively studied within the DESICOS project [58] (new robust DESign guideline for Imperfection sensitive COmposite launcher Structures) in order to develops and validates new deterministic [59], [60], [61] probabilistic [30] as well as experimental [62], [63] design approaches for composite shells [64], [65]. A comprehensive overview regarding this project is for example given in [66].

Lower-bound methods should deliver a theoretical plateau for the buckling load which is equal or less to every buckling load caused by multiple or large-amplitude imperfections [67], [68]. Compared to probabilistic methods, the measurement, stochastic analysis and storage of imperfection data from many tests is not needed if lower-bound methods are applied which saves time and cost during the design process.

This article provides an overview for recent developments in shell buckling analysis and gives design examples for isotropic and composite cylindrical shells under axial compression. The test shells with complete geometry and material description are presented in section 2 . The influence of geometric imperfections on the buckling load of cylindrical shells is studied in section 3. A 
detailed design example for the application of probabilistic methods is given in section 4 . Different numerical and analytical lower-bound methods are demonstrated in section 5. The last section summarizes all main results of the article. It should be noted that all relevant data for this article: measured geometric imperfections, inp-data for the numerical analysis and results are given in the Elsevier repository of this article. 


\section{Test specimens and numerical model}

The shells considered in this paper are unstiffened isotropic and composite cylinders as shown. The isotropic cylinders are classified according to the corresponding manufacturing process and are defined as N (electroplated nickel shells), B (machined brass shells) and ST (welded stainless-steel shells) shells. These shells were tested by Arbocz and Abramovich and details regarding manufacturing, testing and test evaluation are summarized in [23]. The monolithic composite cylinders were manufactured by prepreg hand layup on a mandrel at the German aerospace center in Braunschweig and are defined as $\mathrm{C}$ (composite) shells. The $\mathrm{C}$ shells have different laminate stacking sequences which results in different perfect buckling loads and different imperfection sensitivities. A detailed report regarding the corresponding testing campaign is given by Hühne in the following reference [57].

The material and geometry parameters are summarized in the Table 1 and Table 2 for the isotropic and composite cylinders. Note that for the ST-shells, the squash load according to equation (2) was the reference load which results in a minimum experimental KDF of about 0.67 (for equation (1) the experimental KDF would result to 0.29). The reference load for the composite shells was the perfect buckling load according to a geometrically nonlinear analysis (GNA). The shells were analyzed with the commercial finite element software ABAQUS [69] and a representative numerical model of the unstiffened cylinders is shown in Fig. 3.

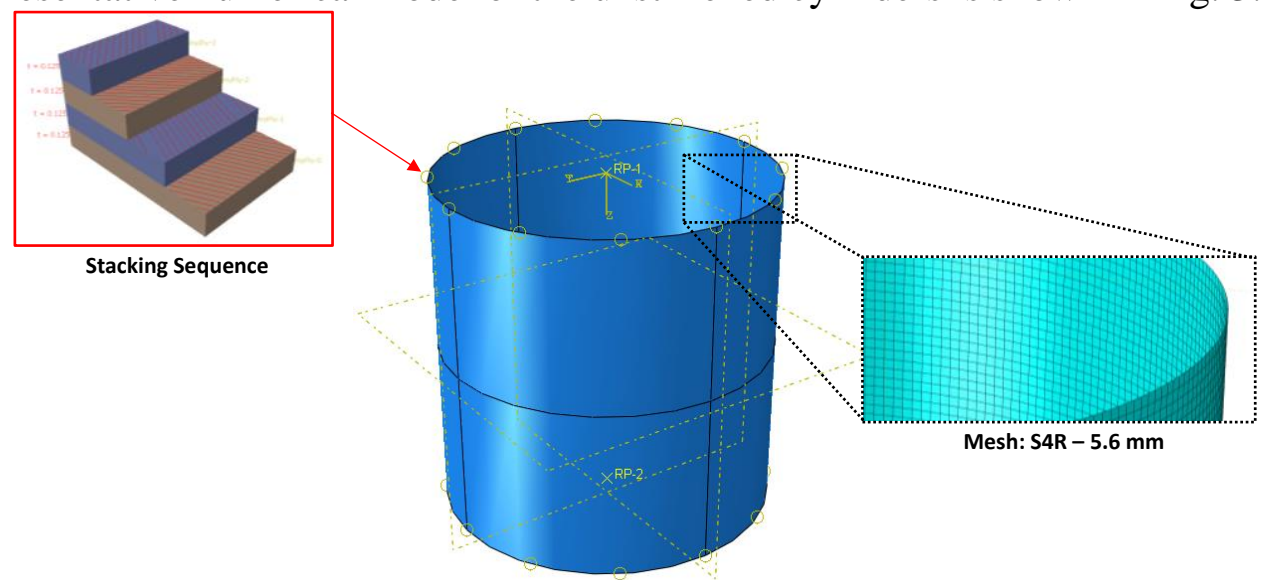

Fig. 3: Numerical model of the cylinder C07

All cylinders were modeled using linear shells elements with reduced integration (S4R) and further details regarding the numerical settings in ABAQUS can be found in the Appendix A. The mechanical boundary conditions on both cylinder edges are defined as clamped by using rigid-body interactions (Tie) which are coupled with a reference point. The displacement in axial direction is free at the top cylinder edge for load application. All inp files for the GNA of the perfect shell are given in the Elsevier repository of this article.

Table 1: Material data for the isotropic cylindrical shells after [23] and for the composite cylinder after [29]

\begin{tabular}{|c|c|c|c|c|c|}
\hline Material parameter & N-Shell & B-Shell & ST-Shell & Material parameter & C-Shells \\
\hline elasticity modulus $E \quad-\left[\mathrm{N} / \mathrm{mm}^{2}\right]$ & 172400 & 106500 & 180600 & elasticity modulus $E_{11^{-}}\left[\mathrm{N} / \mathrm{mm}^{2}\right]$ & 125774 \\
\hline Poisson's ratio $v$ & 0.3 & 0.3 & 0.3 & elasticity modulus $E_{22}-\left[\mathrm{N} / \mathrm{mm}^{2}\right]$ & 10030 \\
\hline Yield Strength Y $-\left[\mathrm{N} / \mathrm{mm}^{2}\right]$ & - & - & 180 & $\begin{array}{l}\text { shear modulus } G_{12}-\left[\mathrm{N} / \mathrm{mm}^{2}\right] \\
\text { Poisson's ratio } v_{12} \\
\text { Ply thickness }-[\mathrm{mm}]\end{array}$ & $\begin{array}{l}5555 \\
0.271 \\
0.125\end{array}$ \\
\hline
\end{tabular}


Table 2: Geometry data for the isotropic cylindrical shells after [23] and for the composite cylinder after [29]

\begin{tabular}{|c|c|c|c|c|c|c|c|c|c|}
\hline Shell & $\mathrm{R}-[\mathrm{mm}]$ & $\mathrm{L}-[\mathrm{mm}]$ & $\mathrm{t}-[\mathrm{mm}]$ & $\mathrm{R} / \mathrm{t}$ & $\mathrm{L} / \mathrm{R}$ & $\mathrm{Z}$ & Laminate Stacking & $\mathbf{N}_{\exp }-[\mathbf{k N}]$ & pexp \\
\hline N-6 & 101.6 & 196.85 & 0.0986 & 1030 & 1.94 & 3689 & - & 2.67 & 0.408 \\
\hline N-9 & 101.6 & 196.85 & 0.0975 & 1042 & 1.94 & 3731 & - & 3.05 & 0.465 \\
\hline $\mathrm{N}-11$ & 101.6 & 196.85 & 0.0978 & 1038 & 1.94 & 3720 & - & 3.90 & 0.595 \\
\hline B-1 & 101.6 & 196.85 & 0.205 & 495 & 1.93 & 1774 & - & 11.32 & 0.665 \\
\hline B-2 & 101.6 & 144.78 & 0.1852 & 548 & 1.42 & 1062 & - & 7.17 & 0.516 \\
\hline B-4 & 101.6 & 140.97 & 0.2634 & 385 & 1.38 & 708 & - & 16.66 & 0.592 \\
\hline ST-1 & 117.86 & 148.59 & 0.4564 & 258 & 1.26 & 391 & - & 56.05 & 0.906 \\
\hline ST-2 & 118.36 & 148.59 & 0.4526 & 261 & 1.26 & 393 & - & 48.50 & 0.784 \\
\hline ST-3 & 117.91 & 148.59 & 0.46 & 256 & 1.26 & 388 & - & 46.80 & 0.756 \\
\hline ST-4 & 118.49 & 148.59 & 0.4554 & 260 & 1.26 & 390 & - & 51.35 & 0.830 \\
\hline ST-5 & 118.49 & 148.59 & 0.4567 & 259 & 1.26 & 389 & - & 49.90 & 0.806 \\
\hline ST-6 & 117.86 & 148.59 & 0.4544 & 259 & 1.26 & 393 & - & 41.70 & 0.674 \\
\hline $\mathrm{C} 07$ & 250.0 & 500.0 & 0.5 & 500 & 2.0 & 2000 & {$[24,-24,41,-41]$} & 21.8 & 0.649 \\
\hline $\mathrm{CO8}$ & 250.0 & 500.0 & 0.5 & 500 & 2.0 & 2000 & {$[24,-24,41,-41]$} & 21.9 & 0.652 \\
\hline C09 & 250.0 & 500.0 & 0.5 & 500 & 2.0 & 2000 & {$[41,-41,24,-24]$} & 15.7 & 0.895 \\
\hline $\mathrm{C} 10$ & 250.0 & 500.0 & 0.5 & 500 & 2.0 & 2000 & {$[24,41,-41,-24]$} & 16.7 & 0.695 \\
\hline C11 & 250.0 & 500.0 & 0.5 & 500 & 2.0 & 2000 & {$[24,41,-41,-24]$} & 15.7 & 0.654 \\
\hline $\mathrm{C} 12$ & 250.0 & 500.0 & 0.5 & 500 & 2.0 & 2000 & {$[45,-45,0,-79]$} & 18.6 & 0.799 \\
\hline
\end{tabular}




\section{Geometric imperfection analysis}

In this section results of geometrically nonlinear analysis with measured geometric imperfections (GNIA) are presented. The GNIA were performed using the commercial finite element software ABAQUS and the corresponding inp-files as well as imperfection data are all given in the Elsevier repository of this article. Note, that the only difference between GNA and GNIA is the additional consideration of any kind of imperfection. The first section of this chapter deals with imperfection signatures of metallic cylinders manufactured by electroplating, machining and welding. In the last section similar studies for monolithic composite cylinders are given.

\subsection{Metallic cylinders}

The input data used for this section are based on an experimental testing campaign of TU Delft which is summarized in the imperfection data bank [23]. This section will mainly focus on the description of measured geometric imperfection by means of Fourier series. For further details regarding the testing [70] and test evaluation of the buckling experiments, the documents by Dancy [27] are recommended.

The initial measured geometric imperfections (MGI) of the metallic shells (see Fig. 4) were measured and the corresponding Fourier coefficients $A_{k l}$ and $B_{k l}$ of the half wave cosine approach are given in [23]. The authors of this article have extracted the Fourier coefficients of the N, B and ST shells of the partially hard to read documents and stored them along with corresponding Python scripts in the Elsevier repository of this article.

The half wave cosine approach [26] is given by the equation (4) and gives an approximation of the imperfect cylinder surface $\mathrm{z}$ of the metallic shells which depends on the cylinder length $\mathrm{L}$, the cylinder radius $\mathrm{R}$, the wall thickness t, the coordinates $x, y$ and the wave numbers $l, k$. The parameters $\mathrm{n}_{1}$ and $\mathrm{n}_{2}$ denote the maximum number of waves included in the series.

$$
z(x, y)=t \sum_{k=0}^{n_{1}} \sum_{l=0}^{n_{2}} \cos \left(k \pi \frac{x}{L}\right) \cdot\left(A_{k l} \cos \left(\frac{l y}{R}\right)+B_{k l} \sin \left(\frac{l y}{R}\right)\right)
$$
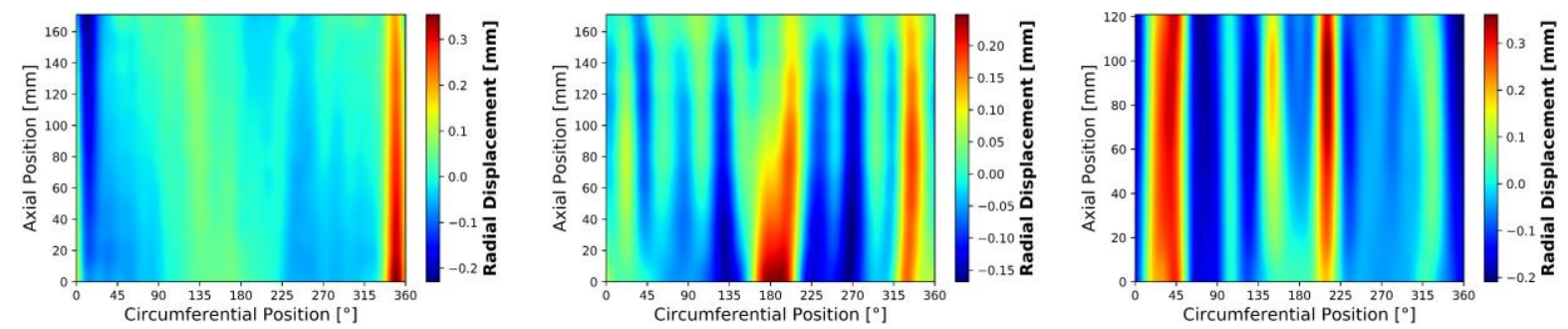

Fig. 4: Geometric imperfection signatures for the shells N6, B1 and ST1 from left to right

The imperfection signatures of the shells N-6, B1, and ST1 are shown in Fig. 4. In order to analyze the imperfection signatures, the square sum according to equation (5) of the corresponding Fourier coefficients is plotted versus the number of the axial and circumferential wave numbers $k$ and $l$.

$$
\xi_{k l}=\sqrt{A_{k l}^{2}+B_{k l}^{2}}
$$

The Fourier coefficients of the N-6, B-1 and ST-1 shells are shown in Fig. 5 for different axial and circumferential wave numbers $k$ and $l$. These figures show that the initial imperfections of 
the electroplated (N-shells) and the machined (B-shells) cylinders are dominated by lower order modes. That is, the amplitudes of the Fourier coefficients which are based on the experimentally measured initial imperfections decay with increasing waver numbers $l$. The highest imperfection amplitude occurs for $l=2$ (out of roundness component). In the case of the ST-shells, the Fourier coefficients with long wave length in axial direction have distinct maxima at 3 circumferential waves.
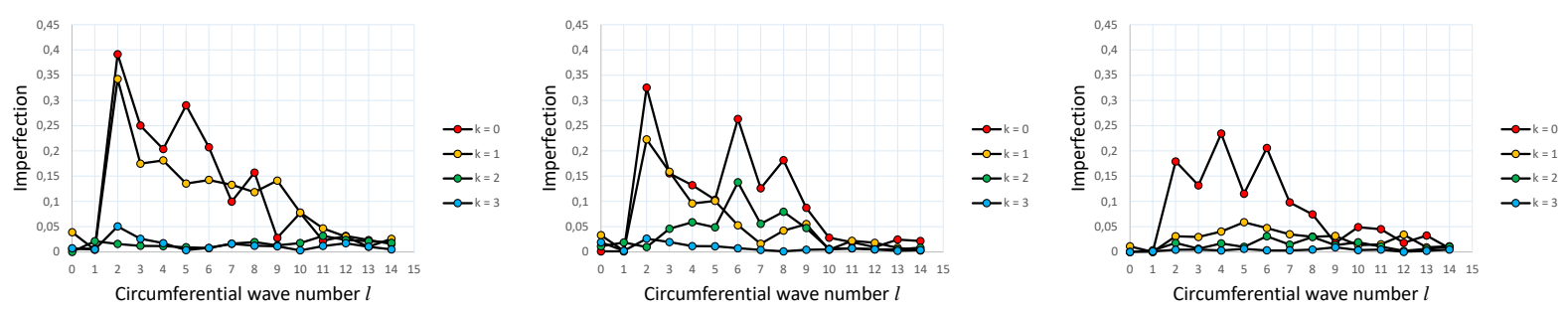

Fig. 5: Fourier coefficients vs. the circumferential wave numbers $l$ for different axial wave numbers $k$ for the shells N6, B1 and ST1 from left to right

The numerical results obtained by a geometrically nonlinear analysis with measured geometric imperfections are shown in Fig. 6 for the $\mathrm{N}$ (left) and B (right) shells for the measured imperfection signatures corresponding to the highest buckling load reduction. The results for the other imperfection signatures are given in the Elsevier repository of this article. The loaddisplacement curves of the perfect shell obtained by a GNA and the minimum experimental buckling load values are also shown in all following load-displacement curves for the purpose of comparison.
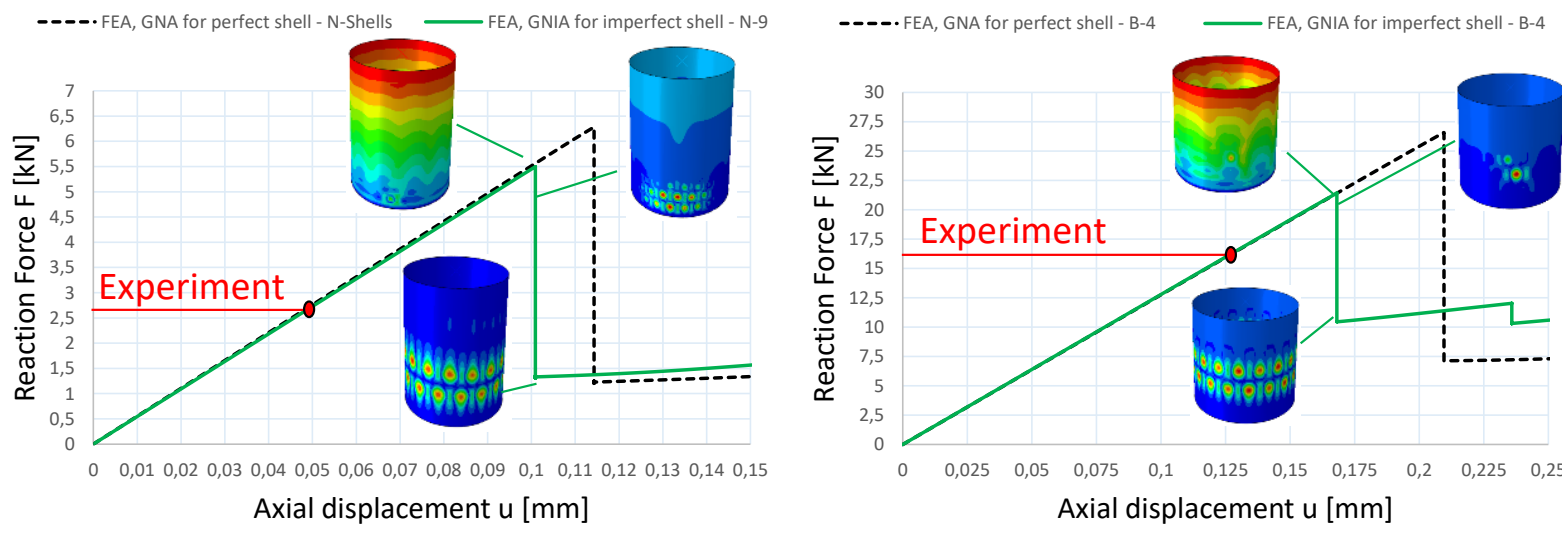

Fig. 6: Load displacement curve for the perfect shell and imperfect shell: N-Shells (left) - B-Shells (right)

The results show that the measured geometric imperfections don't reduce the axial stiffness of the shell. In the case of the N-shells, the highest buckling load reduction occurs for the MGI signature of the shell N-6. However, the buckling load reduction compared to the perfect shell is only about $12 \%$ whereas the experimental buckling load is nearly $60 \%$ lower than the perfect buckling load.

For the B-shells, the MGI signature of B-4 leads to a buckling load reduction of about $24 \%$. The experimental buckling load is about $40 \%$ smaller compared to the perfect buckling load.

Plastic buckling occurred for the ST shells and the corresponding load displacement curves for perfect-plastic material behavior (only yield strength is used and strain rate is 0) are shown in Fig. 7 (left). Also, the load-displacement curves for elastic buckling of the ST-shells are given in Fig. 7 (right) for the purpose of comparison. In the case of plastic buckling, the MGI signature for ST-6 delivers the lowest plastic buckling load. The influence of geometric imperfection is 
not as severe as in the case of pure elastic buckling. The buckling load reduction in the plastic buckling scenario is less than $5 \%$ whereas in the elastic buckling scenario, the buckling load reduction is about $20 \%$. The experimental buckling load is about $30 \%$ smaller compared to the perfect buckling load in the plastic buckling scenario.

Also, the buckling is characterized by the distinct formation of a single dimple in the cylinder surface for elastic buckling of the N, B and ST-shells. For plastic buckling, the edges of the cylinder are more prone to buckling due to the high stresses near the clamping conditions.
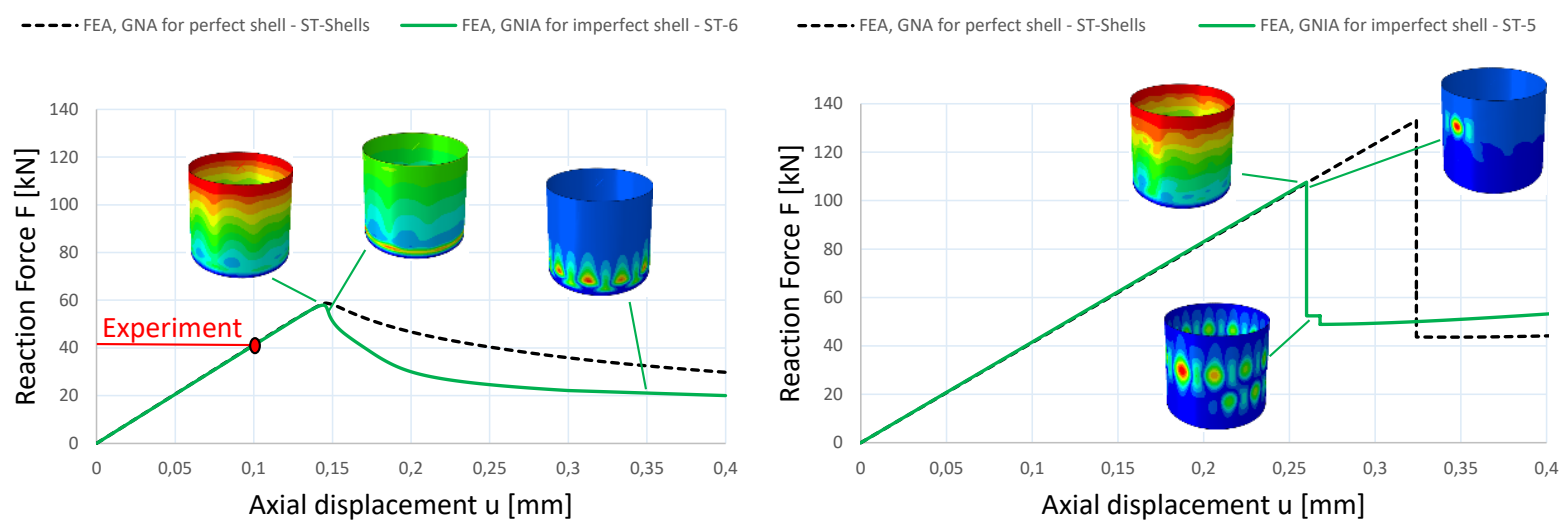

Fig. 7: Load displacement curve for the perfect shell and imperfect shell: ST-Shells \& perfect-plastic material behavior (left) ST-Shells and pure elastic material behavior (right)

\subsection{Composite cylinders}

The measured initial geometric imperfections of the composite shells are also given in the Elsevier repository of this article. For the composite shells, Kriegesmann et al. [47] recommended a different form of the half wave cosine approach (phase shift approach). This approach is given by the equation (6) and eliminates redundancies that are cause by the circumferential positioning of the shell during measurement (for more details see [47]).

The imperfect cylinder surface $\mathrm{z}$ of the composite shells depends in this case on the Fourier coefficients $\xi_{k l}$ and $\varphi_{k l}$, cylinder length $\mathrm{L}$, the cylinder radius $\mathrm{R}$, the wall thickness $\mathrm{t}$, the coordinates $x, y$ and the wave numbers $l, k$. The initial imperfection signatures of the shells $\mathrm{C} 07$ and $\mathrm{C} 12$ are shown in Fig. 8. 


$$
\begin{gathered}
z(x, y)=t \sum_{k=0}^{n_{1}} \sum_{l=0}^{n_{2}} \xi_{k l} \cdot \cos \left(k \pi \frac{x}{L}\right) \cdot \cos \left(\frac{l y}{R}-\varphi_{k l}\right) \\
\xi_{k l}=\sqrt{A_{k l}^{2}+B_{k l}^{2}} \\
\varphi_{k l}=\arctan \left(\frac{B_{k l}}{A_{k l}}\right), \text { for } A_{k l}>0 \\
\varphi_{k l}=\arctan \left(\frac{A_{k l}}{B_{k l}}\right)-\pi, \text { for } A_{k l}<0 \\
\varphi_{k l}=\operatorname{sgn}\left(B_{k l}\right) \cdot \frac{\pi}{2}, \text { for } A_{k l}=0
\end{gathered}
$$
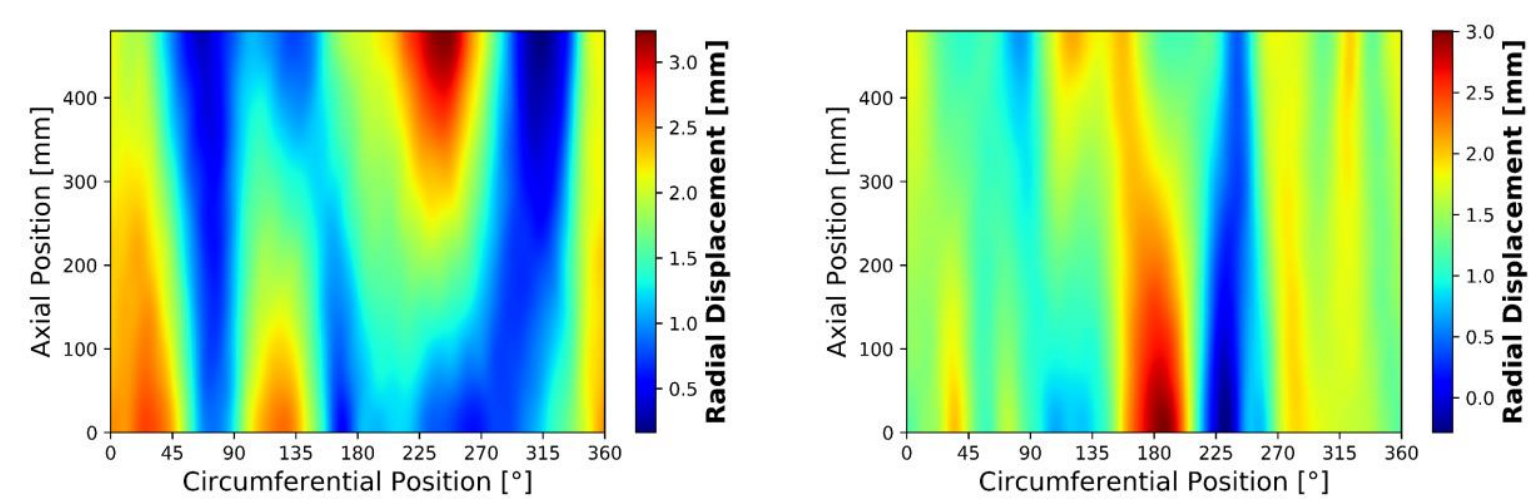

Fig. 8: Geometric imperfection signatures for the shells $\mathrm{C} 07$ and $\mathrm{C} 12$ from left to right
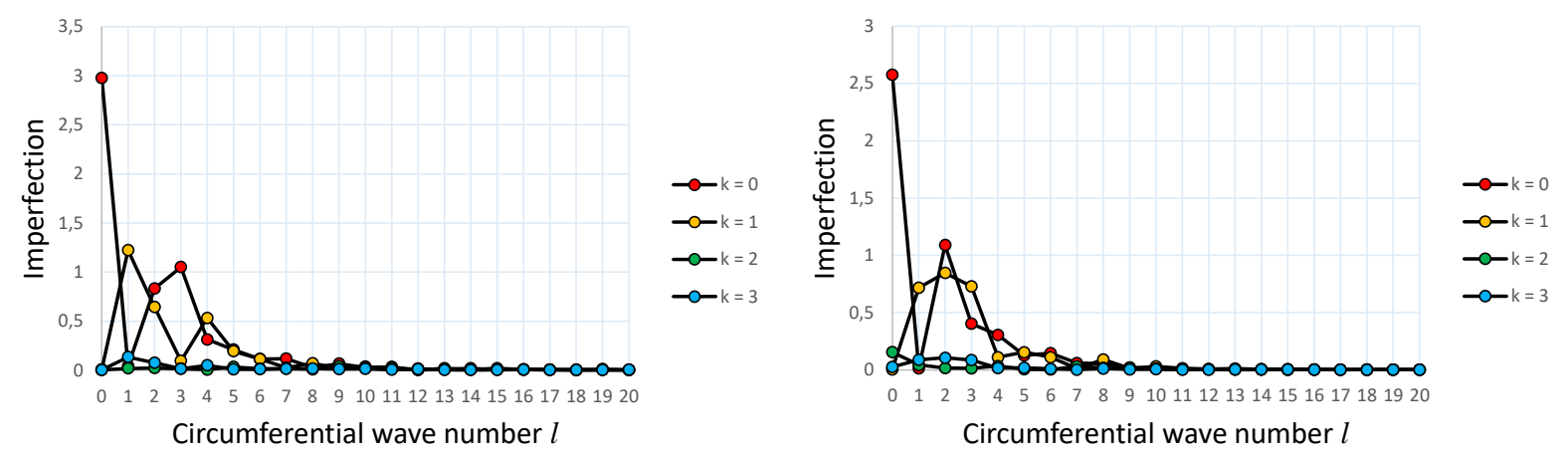

Fig. 9: Fourier coefficients vs. the circumferential wave numbers $l$ for different axial wave numbers $k$ for the shells $\mathrm{C} 07$ and C12 from left to right

The Fourier coefficients of the composite shells are shown in Fig. 9 for different axial and circumferential wave numbers $k$ and $l$. These figures show that the initial imperfections of the composite cylinders are dominated by lower order modes. Especially, the imperfection amplitude for $l \& k=0$ is dominate. 

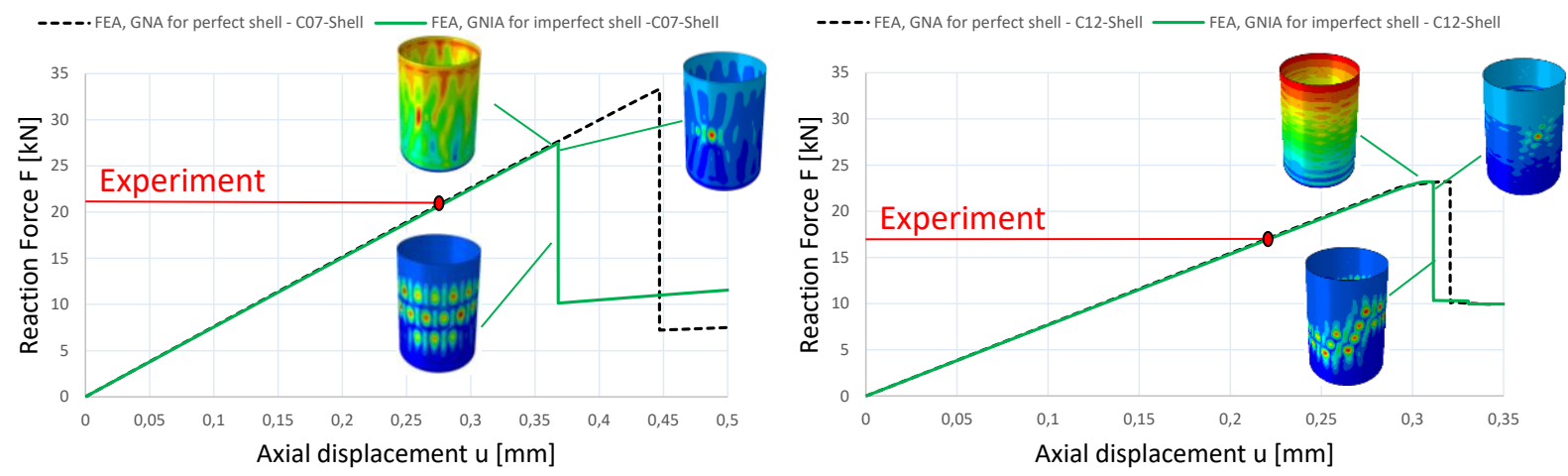

Fig. 10: Load displacement curve for the perfect shell and imperfect shell: composite shells C07 and C12

The imperfection amplitude for $l=2$ (out of roundness component or ovalization) is not as dominate as in the case of the metallic cylinders in section 3.1 which is probably due to the manufacturing on a mandrel.

The results of a geometrically nonlinear analysis with measured imperfections of the composite cylinders $\mathrm{C} 07$ and $\mathrm{C} 12$ are shown in Fig. 10. In the case of the composite shell C07, the MGI signature leads to buckling load reduction of $18 \%$ which is still about $20 \%$ above the experimental buckling load value. The shell $\mathrm{C} 12$ is very insensitive to imperfections and the buckling load reduction is less than $1 \%$ (even for the imperfection signature of C07, the buckling load reduction is only about $2 \%$ ). However, the experimental buckling load of C12 was significantly lower $(18.6 \mathrm{kN})$ which was unexpected. It was assumed that the specimen $\mathrm{C} 12$ was damaged (or something went wrong during the testing) and two additional nominal identical shells to $\mathrm{C} 12$ were built and tested. However, the experimental buckling loads of C13 and C14 were even lower $(17.3 \mathrm{kN}$ and $17.5 \mathrm{kN})$. 


\section{Probabilistic analysis}

In this section a probabilistic design approach is applied to cylinders in order to evaluate the buckling load as a function of the imperfection in a probabilistic manner [71]. A Python script which implements the required equations for the calculations of mean and variance data for a probabilistic analysis with geometric imperfections (section 4.2) is given in the Elsevier repository of this article.

The first-order second-moment method (FOSM) was originally formulated by Rzhanitsyn [48] in 1954 and then independently by Cornell in 1969 [49] (interested reader can also consult with Ref. [50]) and is based on a first-order Taylor approximation of the objective function linearized at the mean values of the random variables $X$. It uses only second-moment statistics (mean values and elements of variances-covariance matrix) of random variables $X$ and ignores information on the distribution (probability density function - PDF) of random variables $X$. FOSM can only be applied if the objective function is linear in the investigated range as shown in Fig. 11. In the case of the stability analysis of cylindrical shells the buckling load $\mathrm{N}$ is the objective function of the probabilistic analysis.

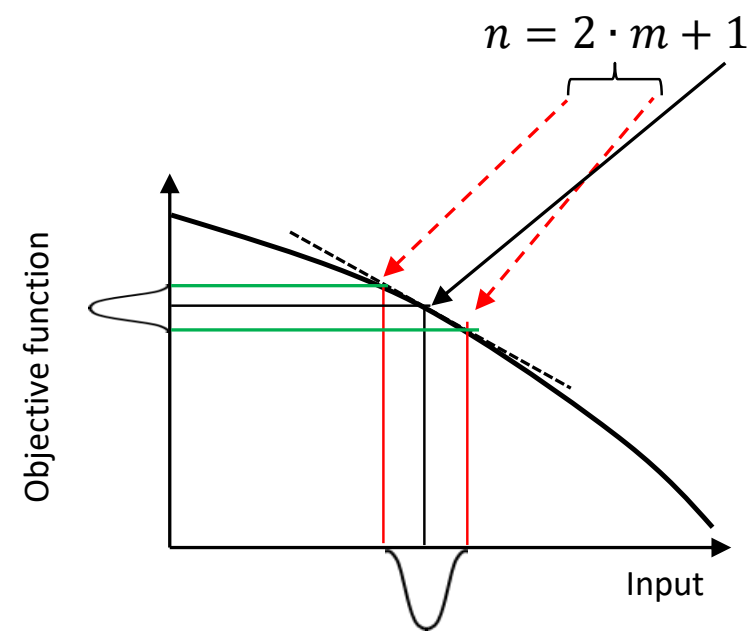

Fig. 11: Illustration of the linearization of the objective function (buckling load) at the mean

\subsection{Analysis with scalar-valued imperfections}

In this section, the N-shells are used to demonstrate the application of FOSM for a stability analysis. The scalar-valued imperfection considered in this section is a wall thickness imperfection which means that the average wall thickness is less than the nominal wall thickness $(0.1 \mathrm{~mm})$ of the cylinder. The mean wall thickness of the N-shells equals to $E(t)=0.0978 \mathrm{~mm}$, the variance $\operatorname{Var}(t)=2.15 \mathrm{e}^{-7} \mathrm{~mm}^{2}$ and the standard deviation of the wall thickness equals to std. $(t)=4.64 \mathrm{e}^{-4} \mathrm{~mm}$. The mean $E$ of the buckling load $N$ can be approximated with equation (7).

$$
E(N(X)) \approx N(E(X))
$$

This equation implies that the mean value $E$ of the buckling load $N$ is calculated using the mean values $E$ of the random variables $X$. In this case the buckling load is determined, and the input variable is the mean wall thickness $E(t)=0.0978 \mathrm{~mm}$. The perfect buckling load equals to 6.55 $\mathrm{kN}$ (with nominal wall thickness $0.1 \mathrm{~mm}$ ) and the buckling load with the mean wall thickness equals to $6.27 \mathrm{kN}$.

The variance of the buckling load $N$ can be determined with equation (8) if the random variables are uncorrelated. 


$$
\operatorname{Var}(N(X)) \approx \sum_{i=1,}^{n} N, X_{i}^{2} \cdot \operatorname{Var}\left(X_{i}\right)
$$

In order to determine the variance of the buckling load $N$ the partial derivatives $N, X_{i}=\frac{\partial N(E(X))}{\partial X_{i}}$ of $N(X)$ and the individual variances $\operatorname{Var}(X)$ of the random variable $X$ are required. The standard deviation std.(X) of the buckling load $N$ is defined according to equation (9).

$$
\text { std. }(N(X))=\sqrt{\operatorname{Var}(N(X))}
$$

The partial derivative $N, x_{i}$ has to be approximated because the buckling load $N$ of the cylinder is determined numerically. The numerical derivative of a function can for example be determined with the central difference method [47] as shown by equation (10).

$$
N, X_{i}=\frac{N\left(E(X)+\Delta z_{X_{i}}\right)-N\left(E(X)-\Delta z_{X_{i}}\right)}{2 \cdot \Delta z_{X_{i}}} \approx \frac{N\left(E(X)+1.5 \cdot s t d .\left(X_{i}\right)\right)-N\left(E(X)-1.5 \cdot s t d .\left(X_{i}\right)\right)}{2 \cdot 1.5 \cdot s t d .\left(X_{i}\right)}
$$

The term $\Delta z_{X_{i}}$ is the increment of the central difference methods and can be defined as $\Delta z_{X_{i}} \approx$ $1.5 \cdot \operatorname{std} .\left(X_{i}\right)$ [47].

In this case the buckling load is determined with ABAQUS and the input variables (wall thickness $\mathrm{t}$ ) for the numerical derivative are defined according to equation (11).

$$
\begin{gathered}
E(t)+1.5 \cdot s t d .(t)=0.0978 \mathrm{~mm}+1.5 \cdot 4.64 \mathrm{e}^{-4} \mathrm{~mm}=0.0984 \mathrm{~mm} \\
N(E(t)+1.5 \cdot s t d .(t))=N(0.0984 \mathrm{~mm})=6.32 \mathrm{kN} \\
E(t)-1.5 \cdot s t d .(t)=0.0978 \mathrm{~mm}-1.5 \cdot 4.64 \mathrm{e}^{-4} \mathrm{~mm}=0.0971 \mathrm{~mm} \\
N(E(t)-1.5 \cdot s t d .(t))=N(0.0971 \mathrm{~mm})=6.18 \mathrm{kN}
\end{gathered}
$$

The resulting buckling loads are used to determine the numerical derivative which is required for the variance and the standard deviation of the buckling load with the scalar-valued wall thickness imperfection. The corresponding equations are defined by equation (12).

$$
\begin{gathered}
N_{t_{t}}=\frac{6.32 \mathrm{kN}-6.18 \mathrm{kN}}{2 \cdot 1.5 \cdot 4.64 \mathrm{e}^{-4} \mathrm{~mm}}=\frac{100.51 \mathrm{kN}}{\mathrm{mm}} \\
\operatorname{Var}(N(t)) \approx N_{, t} \cdot t_{\text {var }} \approx\left(\frac{100.51 \mathrm{kN}}{\mathrm{mm}}\right)^{2} \cdot\left(2.15 \mathrm{e}^{-7} \mathrm{~mm}\right)^{2}=0.0021 \mathrm{kN}^{2} \\
\text { std. }(N(t))=\sqrt{\operatorname{Var}(N(t))}=\sqrt{0.0021 \mathrm{kN}^{2}}=0.046 \mathrm{kN}
\end{gathered}
$$




\subsection{Analysis with vector-valued imperfections}

The random variables $X$ are correlated for the probabilistic analysis of geometric imperfections (Fourier coefficients). In this case the random vector $\boldsymbol{X}$ has to be defined (bold and cursive letter) for the Fourier coefficients and the variance Var of the buckling load $N$ has to be determined with equation (13).

$$
\operatorname{Var}(N(\boldsymbol{X})) \approx \sum_{i=1}^{n_{x}} \sum_{j=1}^{n_{x}} \frac{\partial N}{\partial X_{i}} \frac{\partial N}{\partial X_{j}} \operatorname{Cov}\left(X_{i}, X_{j}\right)
$$

For this equation the covariance matrix $\operatorname{Cov}\left(X_{i}, X_{j}\right)$ and several derivatives have to be determined which can be very costly in terms of computation time and effort. Kriegesmann et al. [47] proposed the Mahalanobis transformation to bypass this problem. The Mahalanobis transformation transforms random variables in a way that they are uncorrelated, have a median of zero and a variance Var of one.

This means, for the probabilistic analysis of the $\mathrm{N}$ shells, that the number of random variables $\mathrm{n}$ for the configuration $\mathrm{n}_{1}=15$ and $\mathrm{n}_{2}=15$ reduces from $n=2 \cdot(15+1) \cdot(15+1)=512$ to $n=$ $(m-1)=3-1=2$. That means the number of random variables reduces by about $99 \%$. The buckling load has to be evaluated $(2 \cdot n)+1=(2 \cdot 2)+1=5$ times for the probabilistic analysis of geometric imperfections. The Mahalanobis transformation is implemented with the following equation (14).

$$
X=\operatorname{Cov}^{\frac{1}{2}} \cdot \mathrm{z}+\mu \text { and } \mathrm{z}=\operatorname{Cov}^{-\frac{1}{2}}(X-\mu)
$$

The random vector $\boldsymbol{X}$ contains in this case the Fourier coefficients $A_{k l}$ and $B_{k l}$, see equation (15).

$$
\boldsymbol{X}=\left(\mathrm{A}_{11}, \mathrm{~A}_{12}, \ldots, \mathrm{A}_{1 \mathrm{n}_{2}}, \ldots, \mathrm{A}_{\mathrm{n}_{1} \mathrm{n}_{2}}, \mathrm{~B}_{11}, \mathrm{~B}_{12}, \ldots, \mathrm{B}_{1 \mathrm{n}_{2}}, \ldots, \mathrm{B}_{\mathrm{n}_{1} \mathrm{n}_{2}}\right)^{T}
$$

The mean vector $\boldsymbol{\mu}$ of the Fourier coefficients is determined as a function of all random vectors $\boldsymbol{X}$ with equation (16).

$$
\boldsymbol{\mu}=\frac{1}{m} \sum_{k=1}^{n} x_{i}^{k}
$$

The application of equation (16) in order to determine the mean imperfection signature of the $\mathrm{N}$ shells is illustrated in Fig. 12. The mean imperfection signature of the $\mathrm{N}$-shells has characteristics of all imperfection signatures but also significantly decreased imperfection amplitudes. The buckling load as a function of the mean geometric imperfection vector equals to $6.04 \mathrm{kN}$. 


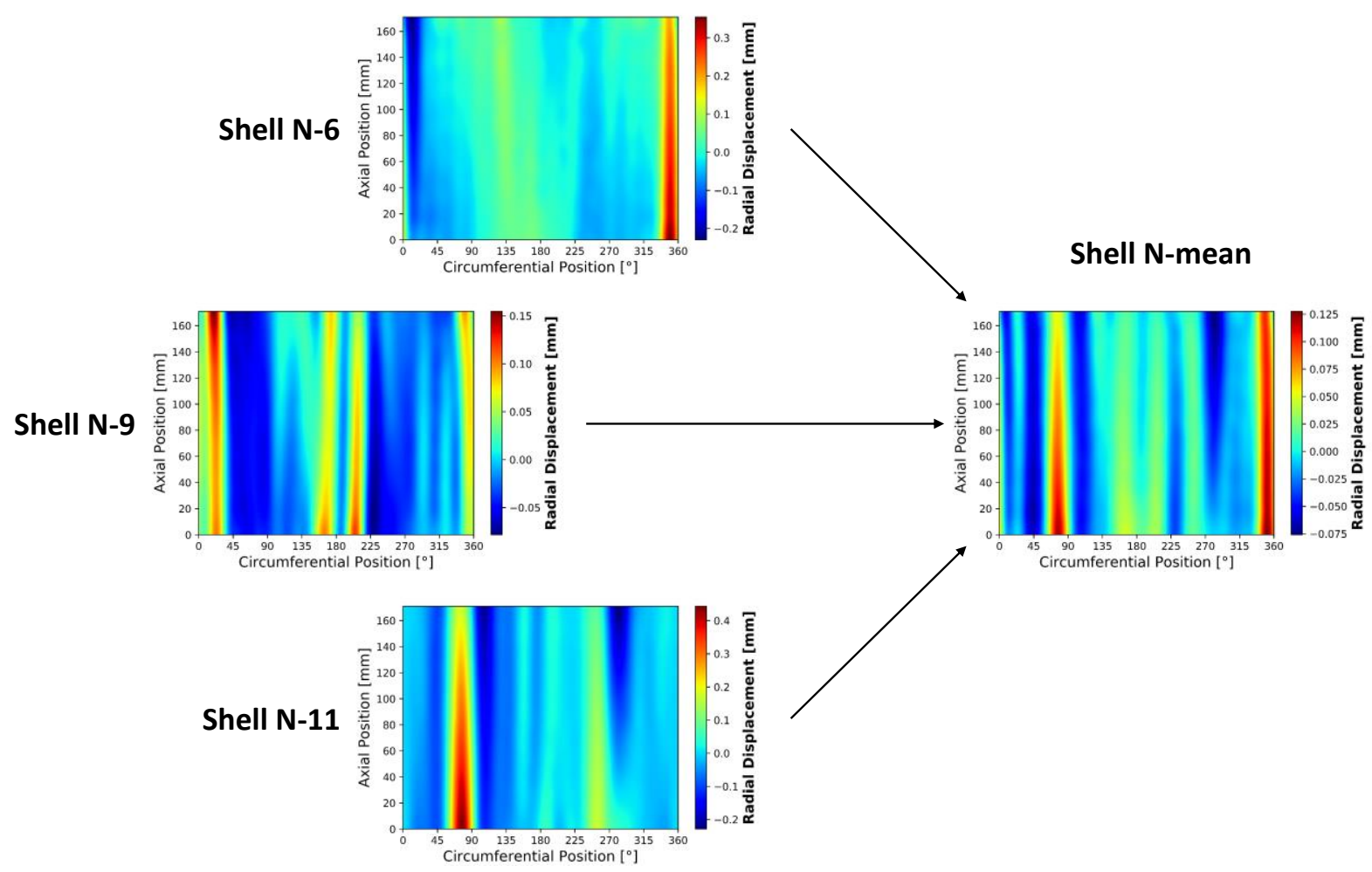

Fig. 12: Geometric imperfection signatures of the shells N-6, N-9 and N-11 (left) mean geometric imperfection signature of the N-Shells (right)

The covariance matrix $\operatorname{Cov}\left(X_{i}, X_{j}\right)$ can be calculated with equation (17).

$$
\operatorname{Cov}\left(X_{i}, X_{j}\right)=\frac{1}{m-1} \sum_{k=1}^{m}\left(x_{i}^{k}-\mu_{i}\right)\left(x_{j}^{k}-\mu_{j}\right)^{T}
$$

The number of data sets $m$ of the random vectors $X$ is in this case smaller than the number of vectors elements $\mathrm{n}$; the covariance matrix is therefore singular. The special Mahalanobis transformation has to be used instead which is given by equation (18).

$$
\boldsymbol{X}=\boldsymbol{B}^{\frac{1}{2}} \mathbf{Z}+\boldsymbol{\mu} \text { and } \mathbf{Z}=\boldsymbol{B}^{-\frac{1}{2}}(\boldsymbol{X}-\boldsymbol{\mu})
$$

The matrix B is defined by equation (19).

$$
\boldsymbol{B}=\boldsymbol{Q D}
$$

The columns of $\mathrm{Q}$ are the eigenvectors of $\operatorname{Cov}\left(X_{i}, X_{j}\right)$ and the diagonal matrix D contains the eigenvalues of $\operatorname{Cov}\left(X_{i}, X_{j}\right)$ as main diagonal elements.

The special Mahalanobis transformation for the probabilistic analysis of the N-shells $(m=3)$ is given as an example with equation (20). 


$$
\begin{gathered}
\boldsymbol{X}_{ \pm \mathbf{1}}=\left[\begin{array}{ccc}
B\left(X_{i}, X_{j}\right) & \cdots & B\left(X_{i}, X_{n}\right) \\
\vdots & \ddots & \vdots \\
B\left(X_{n}, X_{j}\right) & \cdots & B\left(X_{n}, X_{n}\right)
\end{array}\right]^{\frac{1}{2}}\left(\begin{array}{c} 
\pm 1.5 \\
0 \\
\vdots \\
0 \\
0
\end{array}\right)+\boldsymbol{\mu} \\
\vdots \\
\boldsymbol{X}_{ \pm \boldsymbol{n}}=\left[\begin{array}{ccc}
B\left(X_{i}, X_{j}\right) & \cdots & B\left(X_{i}, X_{n}\right) \\
\vdots & \ddots & \vdots \\
B\left(X_{n}, X_{j}\right) & \cdots & B\left(X_{n}, X_{n}\right)
\end{array}\right]^{\frac{1}{2}}\left(\begin{array}{c}
0 \\
0 \\
\vdots \\
0 \\
\pm 1.5
\end{array}\right)+\boldsymbol{\mu}
\end{gathered}
$$

The vector $\mathbf{z}$ has the dimension $\mathrm{n} ; \boldsymbol{X}$ is equivalent to the median vector $\boldsymbol{\mu}$ if $\mathbf{z}$ is equivalent to the zero vector. The elements of $\mathrm{z}$ are equivalent to $1.5\left(\Delta z_{X_{i}} \approx 1.5 \cdot s t d .\left(X_{i}\right)\right)$ because of the Mahalanobis transformation the variance and standard deviation are equal to one. The "scatter" imperfection signatures of the N-shells according to equation (20) are shown in Fig. 13.

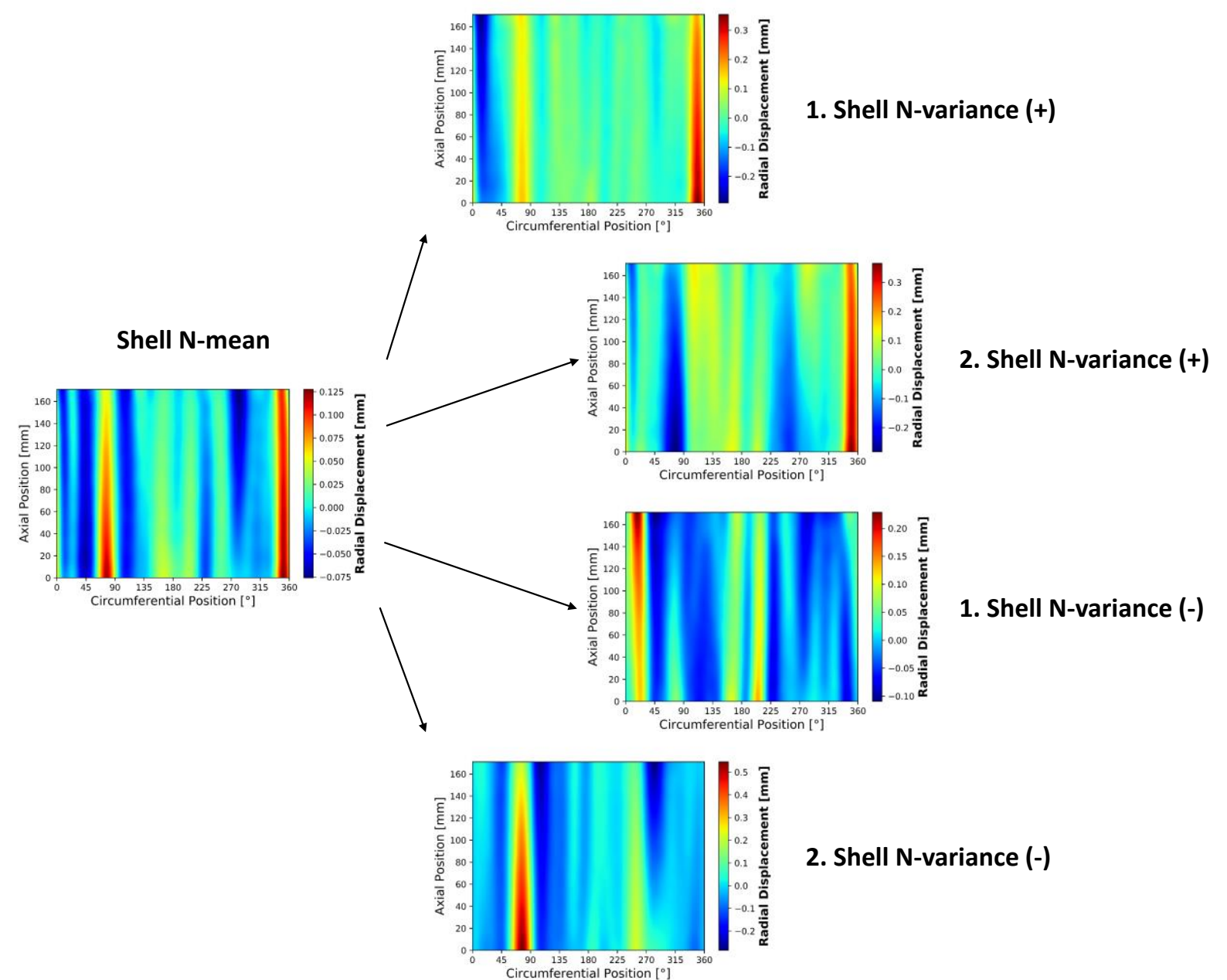

Fig. 13: Mean geometric imperfection signatures of the N-Shells (left) and geometric imperfection signatures generated using the Mahalanobis transformation (right)

The mean imperfection signature of the $\mathrm{N}$-shells is "modified" by using the vector $\mathbf{z}$ which leads to 4 different imperfection signatures which are used to determine the numerical derivatives that are required to determine the variance of the buckling load with measured geometric 
imperfections. This means the buckling load has to be calculated 4 times in the case of the Nshell as shown in equation (21)

$$
\begin{gathered}
N,_{X_{-} 1}=N,_{M G I 1}=\frac{N\left(X_{+1}\right)-N\left(X_{-1}\right)}{2 \cdot 1.5}=\frac{5.60 \mathrm{kN}-5.91 \mathrm{kN}}{2 \cdot 1.5}=-0.113 \mathrm{kN} \\
\vdots \\
N,_{X_{-} n}=N,_{M G I 2}=\frac{N\left(X_{+2}\right)-N\left(X_{-2}\right)}{2 \cdot 1.5}=\frac{5.59 \mathrm{kN}-5.64 \mathrm{kN}}{2 \cdot 1.5}=-0.016 \mathrm{kN}
\end{gathered}
$$

The variance of the buckling load $\mathrm{N}$ for geometric imperfections can then be determined with equation (22).

$$
\begin{gathered}
\operatorname{Var}(N(\boldsymbol{X})) \approx \sum_{i=1}^{n} N_{,_{X_{i}}}^{2} \cdot \operatorname{Var}\left(X_{i}\right)=N_{, X_{i_{-}}}^{2} \cdot 1^{2}+\cdots+N_{, X_{i_{-}}}^{2} \cdot 1^{2} \\
\operatorname{Var}(N(\boldsymbol{M G I}))=N_{, M G I 1}^{2} \cdot 1^{2}+N_{, M G I 2}^{2} \cdot 1^{2}=(-0.113 \mathrm{kN})^{2}+(-0.016 k N)^{2}=0.013 k N^{2}
\end{gathered}
$$

\subsection{Results}

The design load $N_{F O S M}$ of the probabilistic analysis with FOSM is given by equation (23).

$$
N_{F O S M}=E(N(X))-b \cdot s t d .(N(X))=N_{\text {mean }}-b \cdot N_{\text {std. }}
$$

The factor $\mathrm{b}$ defines the chosen reliability limit as well as the assumed type of distribution and is listed in Table 3 for the standard normal distribution.

Table 3: Factor $\mathrm{b}$ for different reliability levels of the standard normal distribution

\begin{tabular}{lcccccc}
\hline Reliability [\%] & 50 & 90 & 99 & 99.9 & 99.99 & 99.999 \\
\hline$b$ & 0 & 1.2815 & 2.3263 & 3.0902 & 3.7190 & 4.2648 \\
\hline
\end{tabular}

In order to calculate $b$ the cumulative density function of the standard normal distribution was inverted and evaluated with a mean of zero and a variance of one for the desired probability level. The mean and the standard deviation of the buckling load for the individual shells are given in Table 4.

Table 4: Mean and standard variation of buckling loads according to FOSM

\begin{tabular}{lcc}
\hline Shells (random variables) & $\mathbf{N}_{\text {mean }}$ [ [kN] & $\mathbf{N}_{\text {std. }}$ [kN] \\
\hline N-Shells (MGI \& t) & 5.947 & 0.118 \\
ST-Shells (MGI \& t \& R) & 58.506 & 0.381 \\
ST-Shells (MGI \& t) & 127.180 & 4.056 \\
[24,-24,41,-41] - C-Shells (MGI) & 27.28 & 1.200 \\
[41,-41,24,-24] - C-Shells (MGI) & 17.38 & 0.128 \\
[24,41,-41,-24] - C-Shells (MGI) & 19.55 & 0.687 \\
[45,-45,0,-79] - C-Shells (MGI) & 23.02 & 0.368 \\
\hline
\end{tabular}

The reliability functions of FOSM are compared to the experimental results of the corresponding cylindrical shells in Fig. 14 (left) for the N and ST shells and in Fig. 14 (right) for the C07 and C12 shells. The results show unfortunately, that FOSM delivers unsatisfying approximations of the experimental reliability functions if only geometric imperfections and deviations of the nominal wall thickness and radius are considered. The mean buckling loads are $30-100 \%$ higher when compared to the experimental results and even for very high reliability levels ( 1 in 100 000), FOSM doesn't deliver conservative design load estimations. 
Results reported in [38], [30] indicate that either imperfect loading conditions or uneven cylinder edges [44] lead to a significantly reduced buckling loads. However, as there are no measurements for "loading" imperfections, they could not be considered in the probabilistic analysis.
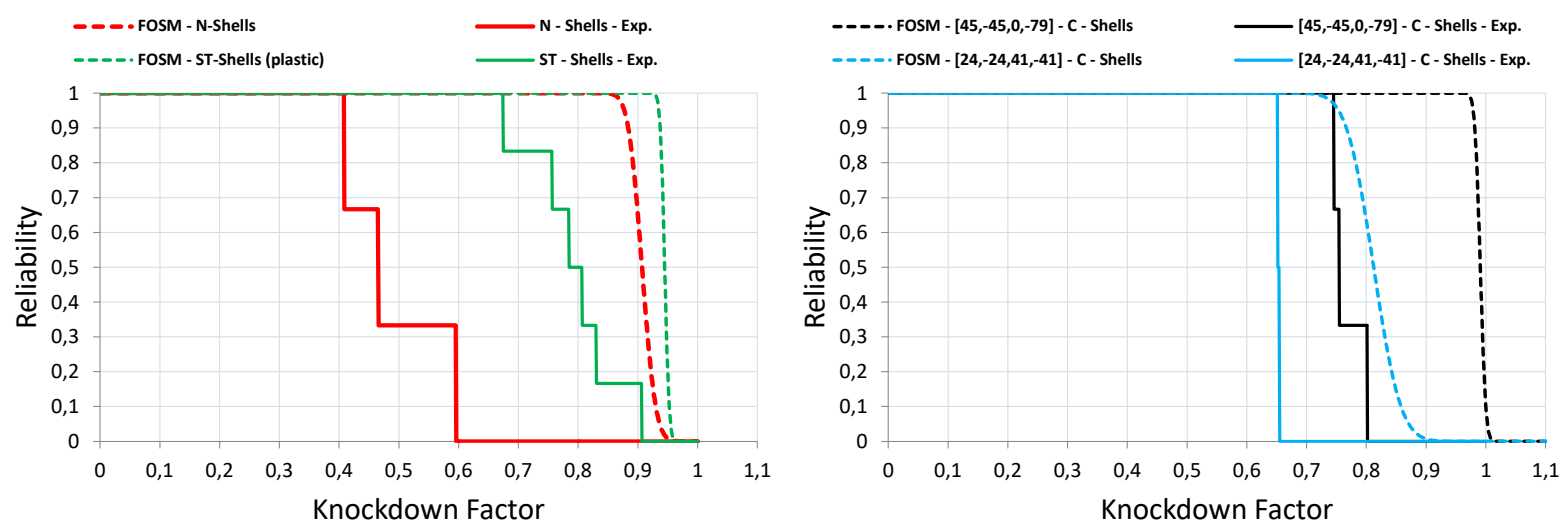

Fig. 14: Reliability functions according to FOSM compared with experimental data: N and ST-shells (left) C12 and C07 shells (right) 


\section{Deterministic lower-bound analysis}

This section presents numerical and analytical lower-bound design examples for the N-Shells (elastic buckling) and the ST-Shells (elastic-plastic buckling). In the first part a numerical analysis of N-Shells with the reduced stiffness method is presented. The corresponding Python scripts for ABAQUS are given in the Elsevier repository. In the second section, analytical lowerbounds which are suitable for elastic buckling are presented. The last section covers analytical design of the ST-Shells which fail due to elastic-plastic buckling.

\subsection{Reduced Stiffness Analysis}

In this section a reduced stiffness analysis for isotropic cylindrical shells under axial compression is performed. The reduced stiffness method (RSM) was developed by Croll et al. [72] and its main purpose is to determine a lower-bound for the buckling load of thin-walled shells [73]. The physical background of the reduced stiffness analysis can be summarized according to Croll et al. [72] as follows:

1. The membrane energy of a shell may be eroded due to the presence of imperfections.

2. The loss of the initially stabilizing membrane energy in a prospective buckling mode is responsible for the buckling load reduction.

3. A lower-bound to the buckling load into a particular buckling mode will be provided by an analysis which excludes the membrane energy.

An improved variant of the RSM was developed by Wagner et al. [74], the localized reduced stiffness method (LRSM). The corresponding results and scripts for ABAQUS-Python are given in the Elsevier Repository for this article.

The LRSM is based on a special membrane stress state in cylinders under compression. For large localized imperfections local buckling of the shells surface and subsequent global buckling occurs (also known as snap-through buckling) as shown in Fig. 15 (left). Snap-through buckling causes a reduction of the membrane stresses at the position of the snap-through to approximately zero (from bottom to top shell edge, see Fig. 15 - right). This behavior is associated with the lower-bound plateau behavior of the critical load for thin-walled shells. The buckling load of a shell is independent from further increasing imperfections (in this specific area) because the membrane stresses are already zero. Further detailed studies regarding the LRSM can be found in [74].
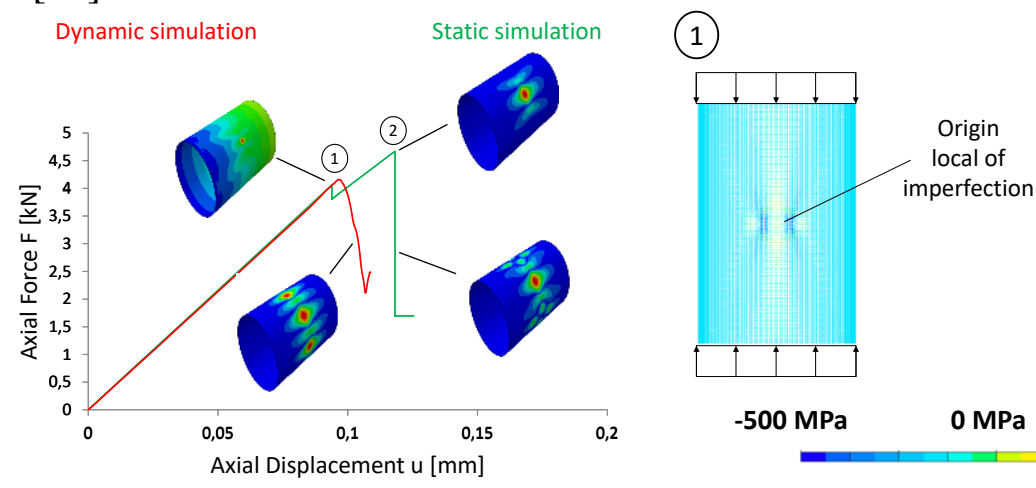

(2)

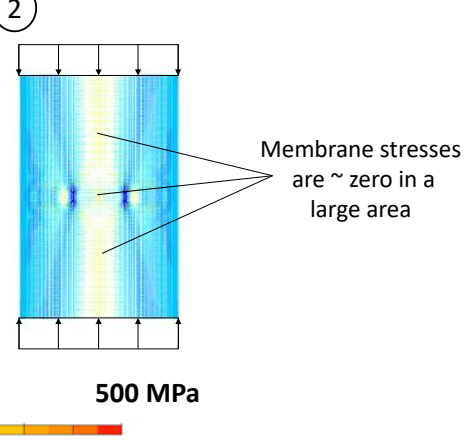

Fig. 15: Load-displacement curve for snap-through buckling (left) membrane stress state of a cylinder (right) from [75]

Within the framework of the LRSM, the membrane stiffness of a shell is reduced in a localized manner in order to approximate the lower-bound membrane stress state. A schematic 
representation of the region considered for reducing the membrane stiffness in a cylindrical shell is shown in Fig. 16.

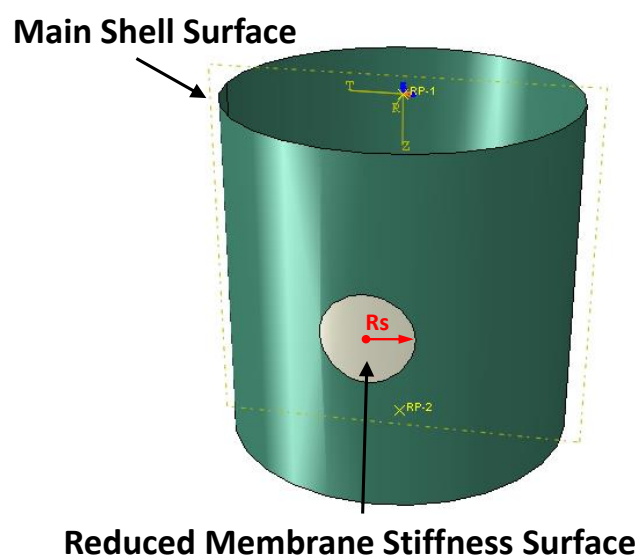

Fig. 16: LRSM surface pattern for the N-shells from [74]

The cylindrical shell has two sections, the main shell surface (green in Fig. 16), and a reduced membrane stiffness surface (white in Fig. 16). On one side, the main shell stiffness is modeled in ABAQUS by using the general shell stiffness definition (homogenous shell thickness or composite stacking). On the other side, the reduced membrane stiffness surface is modeled using the ABD - general shell stiffness matrix and all 9 components of the A - membrane matrix are divided by the membrane stiffness reduction factor $\alpha=1000$ [74]. All the components of the $\mathrm{B}$ - coupling matrix are for isotropic shells equal to 0 . If a composite shell is analyzed with the LRSM, all the components of the B matrix should be set to 0 for the reduced membrane stiffness surface in order to prevent a singular stiffness matrix. Also, the area of the reduced membrane stiffness surface in incrementally increased by increasing the ratio of LRSM radius Rs to cylinder radius $\mathrm{R}$ so its influence on the buckling load can be studied.

The LRSM results are summarized in Fig. 17 (left) for the N-shells, this figure shows the knockdown factor for local and global buckling load values of the $\mathrm{N}$-shells for different $\mathrm{Rs} / \mathrm{R}$ ratios. Even small reduced membrane stiffness surfaces ( $2 \mathrm{~mm}$ - LRSM radius Rs - to $101.6 \mathrm{~mm}$ - cylinder radius $\mathrm{R} \sim \mathrm{Rs} / \mathrm{R}=0.02$ ) lead already to a $20 \%$ reduction of the buckling load.
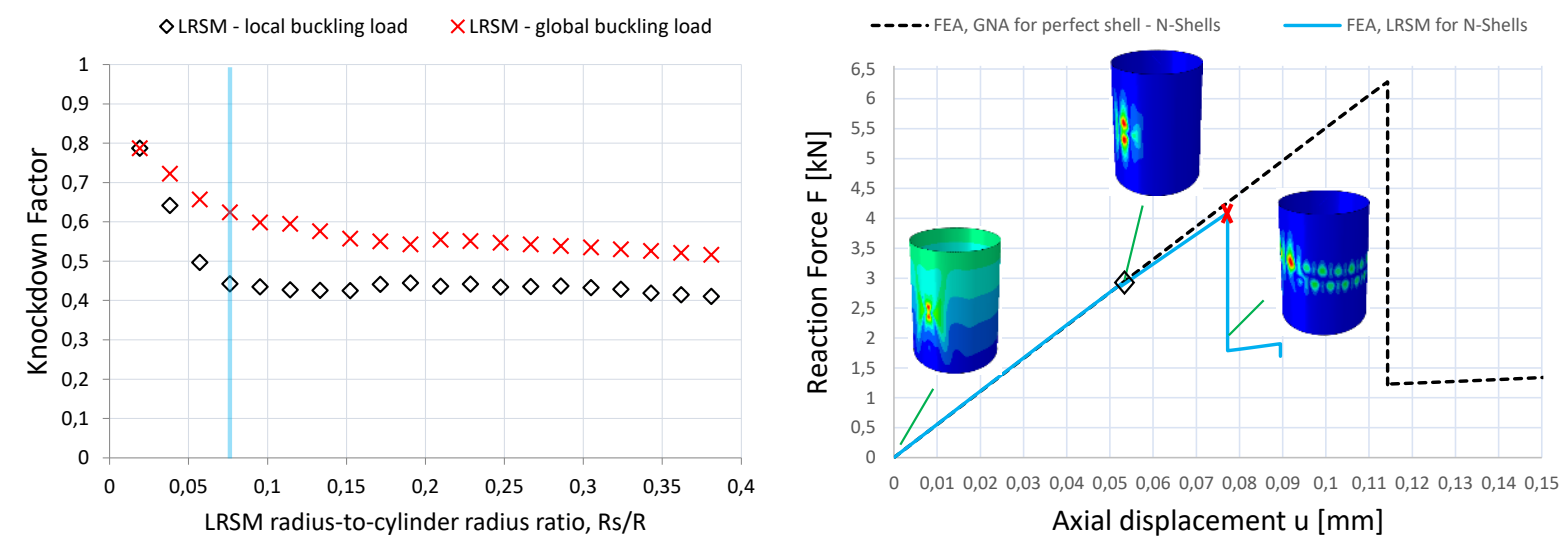

Fig. 17: Lower-bound curves for local and global buckling of the N-Shells for $\alpha=1000$ (left) corresponding load displacement curve (right)

If the Rs/R ratio is increased further, snap-through buckling occurs which leads to local (black diamond in Fig. 17 - right) and subsequent global buckling (red cross in Fig. 17 - right). The local snap-through buckling may already lead to premature collapse of a cylinder which was 
shown by Ludwig et al. [76] by applying dynamic analysis, see Fig. 15 (left). Therefore the local buckling load is used as a design load within the framework of the LRSM. There is a plateau for the local and global buckling load for $\mathrm{Rs} / \mathrm{R}=0.15$ to approximately 0.35 . The minimum KDF for the local buckling load equals to about 0.42 for the $\mathrm{N}$-shells.

The lower-bound curves of the C-shells are shown in Fig. 18 (left), the minimum KDFs for local buckling vary between 0.45 and 0.8 (although they have the same geometry configuration) which means that the LRSM considers the different imperfection sensitivities of the different laminate stacking sequences [77]. Also, the LRSM delivers for every shell (of section 2) conservative buckling load estimations when compared with the experimental results as shown in Fig. 18 (right).
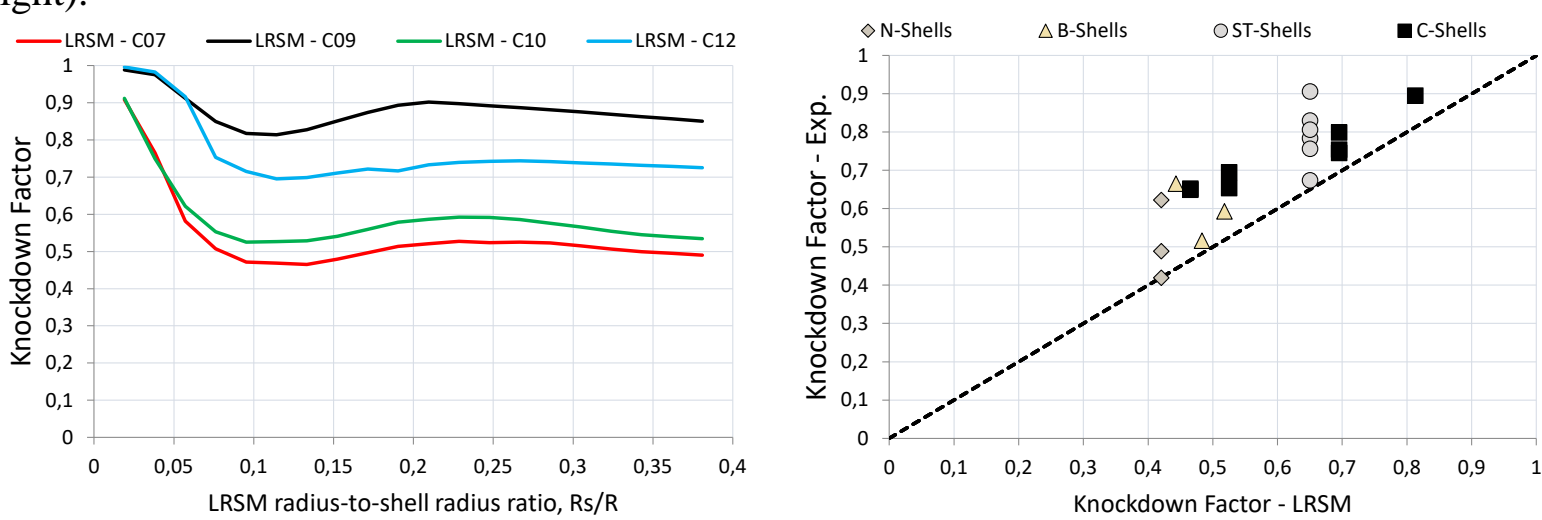

Fig. 18: Lower-bound curves according to LRSM for C-Shells (left) comparison of LRSM results with corresponding exp. Results (right)

\subsection{Analytical design for elastic buckling}

In this section analytical and empirical lower-bounds for the design of cylindrical shells are presented. Weingarten et al. [10] developed a lower-bound curve in 1964 which is recommended in the NASA SP-8007 (see Fig. 19) Space vehicle design criteria [78], see equation (24). This equation is based on a statistical evaluation of early buckling experiments and depends on the shell slenderness (radius-to-thickness ratio, R/t). A collection of other similar empirical design criteria is given by Elishakoff in [34].

$$
\rho=1-0.902 \cdot\left(1-e^{-\left(\frac{1}{16} \sqrt{\frac{R}{t}}\right)}\right)
$$

The Threshold design curve was developed by Wagner et al. [79], [80], [81] and is based on a combined boundary perturbation [82], [83] and probabilistic analysis of cylindrical shells under axial compression. The corresponding equation (25) depends on the $R / t$ ratio as well as the $L / R$ ratio [84].

$$
\begin{gathered}
\rho=\Omega_{\mathrm{TH}} \cdot(R / t)^{-\eta_{T H}} \\
\Omega_{\mathrm{TH}} \approx-0.0196 \cdot\left(\frac{\mathrm{L}}{\mathrm{R}}\right)^{2}-0.0635 \cdot\left(\frac{\mathrm{L}}{\mathrm{R}}\right)+1.3212 \\
\eta_{\mathrm{TH}} \approx-0.013 \cdot\left(\frac{\mathrm{L}}{\mathrm{R}}\right)^{2}+0.061 \cdot\left(\frac{\mathrm{L}}{\mathrm{R}}\right)+0.08
\end{gathered}
$$

All experimental KDFs of the N, B, ST and C-shells are shown in Fig. 19 (left) along with the NASA SP-8007 and the Threshold design curve. The Threshold design curve is conservative for all presented shells and delivers especially for short and thin shells significantly improved KDF 
for the buckling load. In the case of N-Shells the TH curve delivers about $100 \%$ higher KDF for the buckling load compared to the NASA SP-8007.

Evkin [85] showed that the Batdorf parameter $\mathrm{Z}$ according to equation (26) is sufficient to describe cylindrical shells under axial compression (reduction from a 2 variable problem to a 1 variable problem) and derived lower-bounds for cylindrical shells with different boundary conditions [86].

$$
\mathrm{Z}=\frac{\mathrm{L}^{2} \cdot \sqrt{\left(1-v^{2}\right)}}{R \cdot t}
$$

The corresponding KDFs are also given by equation (27) and are shown in Fig. 19 (right).

$$
\rho=1.23 \cdot(Z)^{-0.138}
$$

Also, Groh et al. [87], [88] derived recently a design lower-bound for cylindrical shells which depends only on the Batdorf parameter $\mathrm{Z}$, see equation (28).

$$
\rho=1.48 \cdot(Z)^{-0.16}
$$

Furthermore, Wagner et al. [74] presented another lower-bound which is based on the LRSM and is given by equation (29).

$$
\rho=1.58 \cdot(Z)^{-0.17}
$$

The lower-bounds in Fig. 19 (right) are very similar, the LRSM curve by Wagner is basically equal to the design curve by Groh. The threshold curve and the design curve by Evkin have slightly lower KDF than the lower-bound by Groh et al. especially for $Z<1000$.
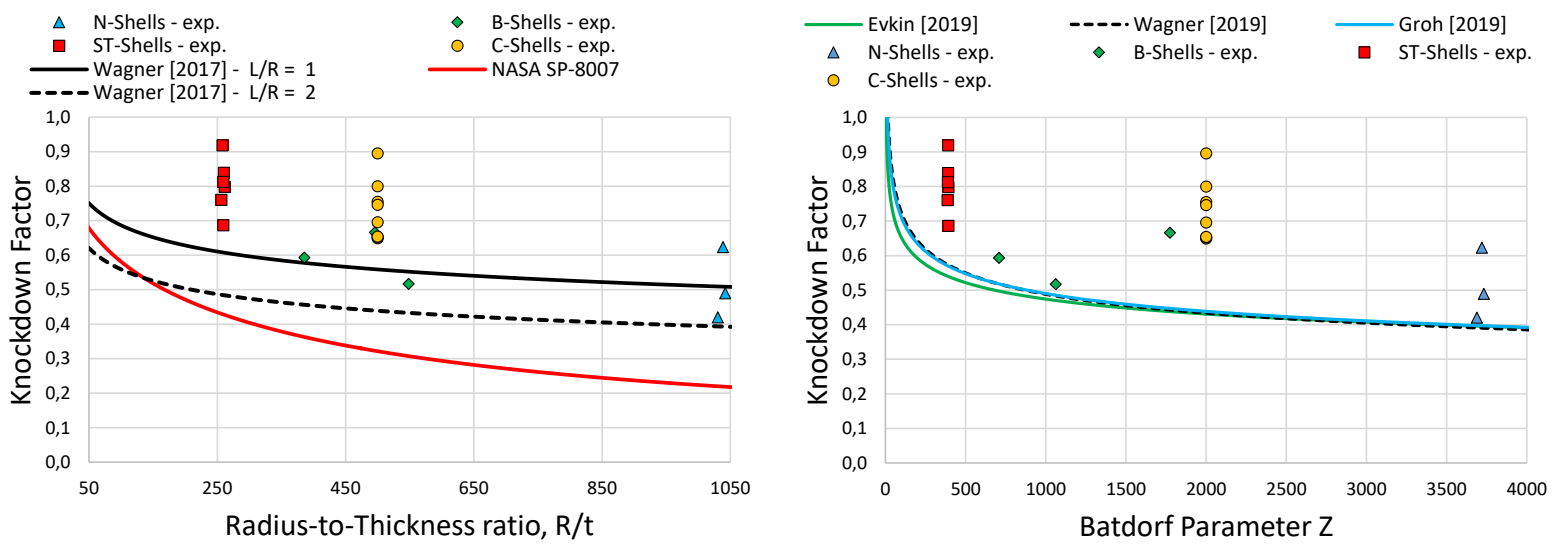

Fig. 19: Empirical knockdown factors for the design of cylindrical shells

\subsection{Analytical design for elastic-plastic buckling}

In this section the framework of the Reference Resistance Design (RRD) by Rotter et al. [89] as a method to design thin-walled cylindrical shells under axial load is presented (Eurocode EN 1993-1-6). The RRD is based on the capacity curve which relates a shell's dimensionless characteristic resistances to its dimensionless slenderness as shown in Fig. 20 (left). The governing equations are set out in terms of the shell buckling Eurocode requirements, which are described in [90], [91], [92], [93], [94] and are also summarized in the Elsevier repository of this article.

The ST-Shells (from section 2) are used to demonstrate the RRD for cylindrical shells which buckle in the elastic-plastic region. In the first step the shell segment length parameter $\omega$ according to equation (30) is determined in order to define the shell length type of the STShells. 


$$
\begin{gathered}
\omega=\frac{L}{\sqrt{R \cdot t}}=\frac{148.59 \mathrm{~mm}}{\sqrt{117.86 \mathrm{~mm} \cdot 0.4544 \mathrm{~mm}}}=20.30 \\
\omega<1.7 \text { for short shells } \\
1.7<\omega<0.5 \cdot \frac{R}{t} \text { for medium length shells } \\
1.7<\omega<0.5 \cdot 259.37=129.68
\end{gathered}
$$

The ST-shells are classified as medium length shells because $\omega=20.3>1.7 \&<129.68$. The elastic critical buckling stress should be determined by using equation (31) which depends on the parameter $\mathrm{C}_{\mathrm{x}}$.

$$
\begin{gathered}
\sigma_{\mathrm{x}, \mathrm{Rcr}}=0.605 \cdot E \cdot \frac{t}{R} \cdot C_{x} \\
\mathrm{C}_{\mathrm{x}}=1.36-\frac{1.83}{\omega}+\frac{2.07}{\omega^{2}} \text { for short shells } \\
\mathrm{C}_{\mathrm{x}}=1 \text { for medium length shells } \\
\sigma_{\mathrm{x}, \mathrm{Rcr}}=0.605 \cdot 180600 \frac{\mathrm{N}}{\mathrm{mm}^{2}} \cdot \frac{0.4544 \mathrm{~mm}}{117.86 \mathrm{~mm}} \cdot 1=421.25 \frac{\mathrm{N}}{\mathrm{mm}^{2}}
\end{gathered}
$$

In the next step the relative slenderness $\lambda$ (ratio of yield stress $f_{y, k}$ to buckling stress $\sigma_{\mathrm{x}, \mathrm{Rcr}}$ ) is determined with equation (32).

$$
\lambda=\sqrt{\frac{f_{y, k}}{\sigma_{\mathrm{x}, \mathrm{Rcr}}}}=\sqrt{\frac{180.6 \mathrm{~N} / \mathrm{mm}^{2}}{421.25 \mathrm{~N} / \mathrm{mm}^{2}}}=0.654
$$

In the subsequent step the elastic imperfection factor $\alpha$ after equation (33) is required which depends on the characteristic imperfection amplitude $\mathrm{w}_{\mathrm{k}}$ for different manufacturing qualities (excellent quality $\mathrm{Q}=40$, high quality $\mathrm{Q}=25$, normal quality $\mathrm{Q}=16$ ). The elastic imperfection factor $\alpha_{\text {current }}$ is based on studies by Rotter et al. and is currently used in the RRD. A new improved version of the elastic imperfection factor $\alpha_{\text {new }}$ was developed by Wagner in [75]. The difference between the new and current version of the elastic imperfection factor is shown in Fig. 20 (right). The elastic imperfection factor $\alpha_{\text {new }}$ delivers on average 15-20\% higher values when compared to the currently used version.

It should be noted that the RRD neglects the influence of the $\mathrm{L} / \mathrm{R}$ ratio on the lower-bound buckling load and only depends on the $\mathrm{R} / \mathrm{t}$ ratio. The new elastic imperfection factor by Wagner is based on the SBPA $(\mathrm{Q}=40)$ and the post-buckling load $(\mathrm{Q}=16)$ for shells with $\mathrm{L} / \mathrm{R}=2$ which should cover a wide range of civil engineering applications. 


$$
\begin{gathered}
\Delta \mathrm{w}_{\mathrm{k}}=\frac{1}{Q} \cdot \sqrt{\frac{R}{t}}=\frac{1}{40} \cdot \sqrt{\frac{117.86 \mathrm{~mm}}{0.4544 \mathrm{~mm}}}=0.402 \\
\alpha_{\text {current }}=\frac{0.62}{1+1.91 \cdot\left(\Delta \mathrm{w}_{\mathrm{k}}\right)^{1.44}}=\frac{0.62}{1+1.91 \cdot(0.402)^{1.44}}=0.409 \\
\alpha_{\text {new }}=\frac{1}{1+2.6 \cdot\left(\Delta \mathrm{w}_{\mathrm{k}}\right)^{0.8}}=\frac{1}{1+2.6 \cdot(0.402)^{0.8}}=0.443
\end{gathered}
$$
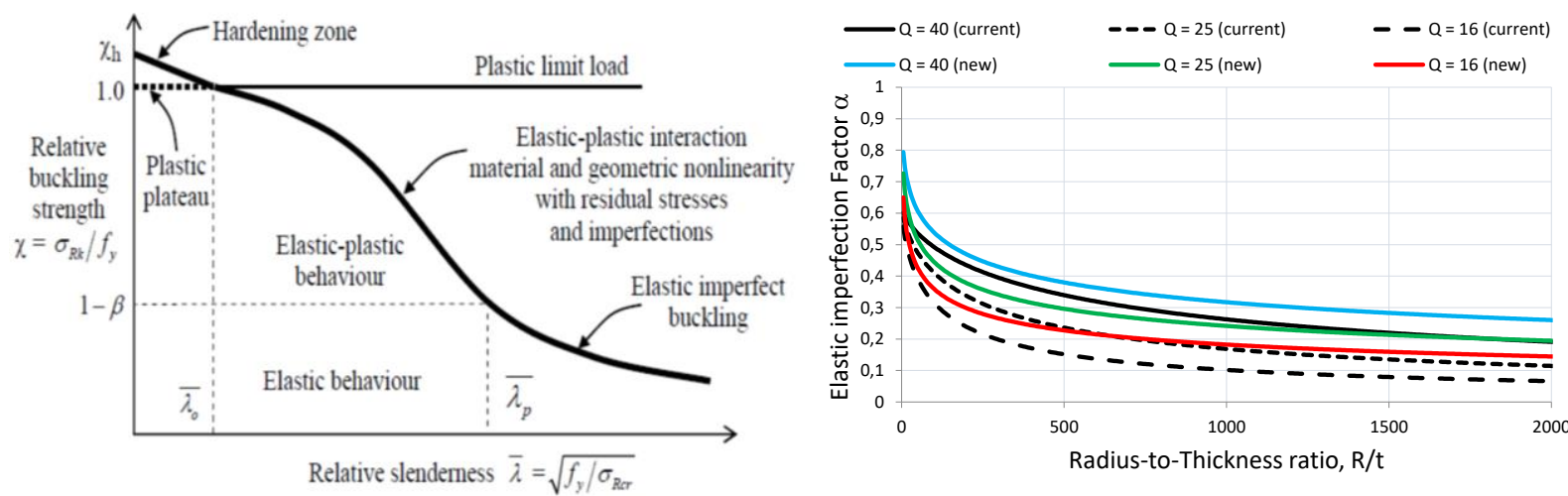

Fig. 20: Capacity curve of the RRD after [89] (left) Current and new Elastic imperfection factors for the design of cylindrical shells according to the RRD (right)

Next the shell class has to be determined, which is defined by comparing the relative slenderness $\lambda$ with the squash limit $\lambda_{0}$ and plastic limit relative slenderness $\lambda_{\mathrm{p}}$. For cylindrical shells under axial compression the squash limit relative slenderness $\lambda_{0}$ is defined as $\lambda_{0}=0.2$ and the plastic limit relative slenderness $\lambda_{\mathrm{p}}$ is given by the following equation (34):

$$
\begin{gathered}
\lambda_{\mathrm{p}_{\text {_current }}}=\sqrt{\frac{\alpha_{\text {current }}}{1-\beta_{\mathrm{r}}}}=\sqrt{\frac{0.409}{1-0.6}}=1.01 \\
\lambda_{\mathrm{p}_{-} \text {new }}=\sqrt{\frac{\alpha_{\text {new }}}{1-\beta_{\mathrm{r}}}}=\sqrt{\frac{0.443}{1-0.6}}=1.05
\end{gathered}
$$

The term $\beta_{\mathrm{r}}$ in equation (34) is the plastic range factor and is defined as $\beta_{\mathrm{r}}=0.6$ and the shell class equals to elastic-plastic buckling because $\lambda<\lambda_{p}$ and the interaction component $\eta$ is set to 1 . The stability reduction factor $\chi$ can be determined with equation (35).

$$
\begin{gathered}
\chi_{\text {current }}=1-\beta_{\mathrm{r}} \cdot\left[\frac{\lambda-\lambda_{0}}{\lambda_{\mathrm{P}_{\text {current }}}-\lambda_{0}}\right]^{\eta}=1-0.6 \cdot\left[\frac{0.654-0.2}{1.01-0.2}\right]^{1}=0.663 \\
\chi_{\text {new }}=1-\beta_{\mathrm{r}} \cdot\left[\frac{\lambda-\lambda_{0}}{\lambda_{\mathrm{P}_{\text {new }}}-\lambda_{0}}\right]^{\eta}=1-0.6 \cdot\left[\frac{0.654-0.2}{1.05-0.2}\right]^{1}=0.680
\end{gathered}
$$

Finally, the design buckling resistance $\sigma_{\mathrm{x}, \mathrm{Rd}}$ can be determined with equation (36).

$$
\begin{gathered}
\sigma_{\mathrm{x}, \text { Rd_current }}=\chi_{\text {current }} \cdot \sigma_{\mathrm{x}, \mathrm{Rcr}}=0.663 \cdot 421.25 \frac{\mathrm{N}}{\mathrm{mm}^{2}}=119.86 \frac{\mathrm{N}}{\mathrm{mm}^{2}} \\
\sigma_{\mathrm{x}, \text { Rd_new }}=\chi_{\text {new }} \cdot \sigma_{\mathrm{x}, \mathrm{Rcr}}=0.68 \cdot 421.25 \frac{\mathrm{N}}{\mathrm{mm}^{2}}=122.81 \frac{\mathrm{N}}{\mathrm{mm}^{2}}
\end{gathered}
$$

The corresponding design load can be determined according to equation (37) 


$$
\begin{gathered}
\mathrm{N}_{\mathrm{x}, \text { Rd_current }}=2 \cdot \pi \cdot R \cdot t \cdot \sigma_{\mathrm{x}, \text { Rd_current }}=2 \cdot \pi \cdot 117.86 \mathrm{~mm} \cdot 0.4544 \mathrm{~mm} \cdot 119.86 \frac{\mathrm{N}}{\mathrm{mm}^{2}}=40.33 \mathrm{kN} \\
\mathrm{N}_{\mathrm{x}, \mathrm{Rd} \_ \text {new }}=2 \cdot \pi \cdot R \cdot t \cdot \sigma_{\mathrm{x}, \mathrm{Rd}_{\text {new }}}=2 \cdot \pi \cdot 117.86 \mathrm{~mm} \cdot 0.4544 \mathrm{~mm} \cdot 122.81 \frac{\mathrm{N}}{\mathrm{mm}^{2}}=41.32 \mathrm{kN}
\end{gathered}
$$

In the case of $\mathrm{Q}=40, \mathrm{Q}=25$ and $\mathrm{Q}=16$, the new elastic imperfection factor leads to increased design loads which are $2.4 \%, 5.7 \%$ and $17.6 \%$ higher than the design loads according to the currently used RRD. 


\section{Conclusion and Outlook}

In this articles covers design examples for isotropic and composite cylindrical shells under axial compression. The application of measured geometric imperfection (MGI) signatures is for the analyzed shells not reliable because the corresponding test buckling loads are most of the time underestimated as shown in Fig. 21.

A probabilistic analysis with geometric and wall thickness imperfections was demonstrated and the corresponding stochastic moments (mean and variance) of the buckling load were determined. However, even for very high reliability levels, the probabilistic analysis delivers non-conservative buckling load estimations.
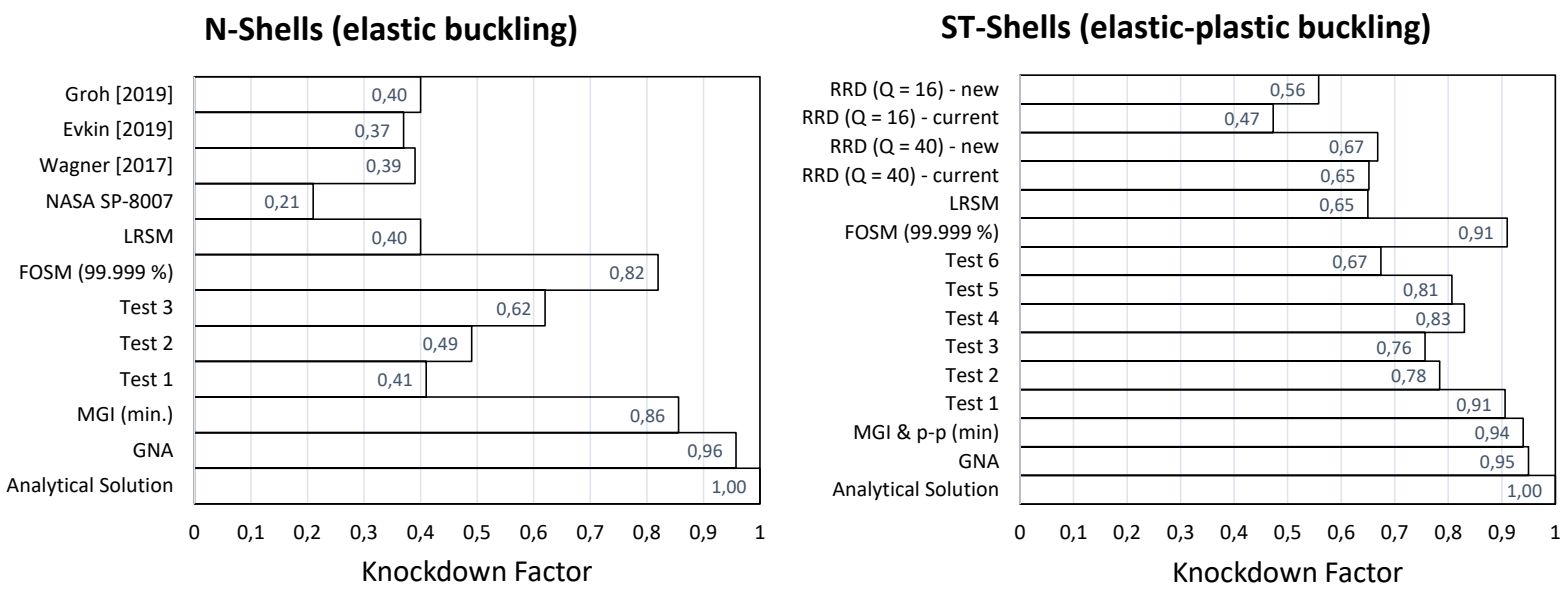

Fig. 21: Comparison of KDF for the N-Shells (left) and ST-Shells (right)

A reduced stiffness analysis (RSA) for cylindrical shells under axial compression was presented in section 5 in order to study the lower-bound behavior. The localized reduced stiffness method (LRSM) delivers always higher KDFs than the NASA SP-8007 and yet conservative buckling load estimations (when compared with experimental results).

Recently developed lower-bound curves for the design of axially loaded cylinders were also presented and compared with the NASA SP-8007 and experimental results. Although, the lowerbounds by Evkin, Wagner and Groh were all derived independently, they are based on the idea of localized buckling and deliver similar KDF for the lower-bound buckling load.

The reference resistance design according to the EN 1993-1-6 was presented for shells which buckle in the elastic-plastic region. New elastic imperfection factors are presented which deliver improved KDFs in comparison to the currently used design factors as shown in Fig. 21 (right). The results of this article were mainly obtained by using the commercial FEA software ABAQUS and all inp-data, imperfection files, Python scripts and results are summarized in the Elsevier repository of this article.

\section{Acknowledgements}

This work is dedicated to Johann Arbocz who passed away on 15 July 2019. 


\section{Appendix A - Abaqus-Python script manual}

In this section, a brief overview over the ABAQUS-Python script used in this article is given. The scripts were tested on ABAQUS 6.14 to ABAQUS 2019 and Spyder (Python 3.7). It is proposed to use the Anaconda Distribution as Python Science Platform from the website:

https://www.anaconda.com/distribution/

The ABAQUS-Python script can be used to study the lower-bound buckling load of cylindrical and conical shells (see line 655 and variable mySemi_Vertex_Angle) under axial compression (or pure bending by slightly modifying the Python script, see line 832-850).

The name of the ABAQUS-Python script is:

Cone_LRSM_clamped_FC_007.py

The ABAQUS-Python script has 4 different sections:

1. Section for functions

2. Section for data input:

a. Name of the Finite Element Analysis Modell

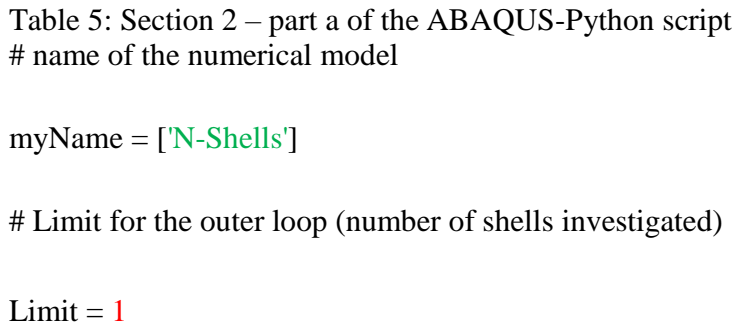

b. Material

Table 6: Section 2 - part b of the ABAQUS-Python script \# Layup and number of plies

myLaminate $1=[45,-45,0,90,90,0,-45,45]$

myLayerNumber_v $=[$ len $($ myLaminate 1$)]$

myShell $=[$ myLaminate 1$]$

\# Material parameter

myE1_v $=[172400]$

myE2_v $=[172400]$

myG12_v $=[172400 /(2 *(1+0.3))]$

myNu12_v $=[0.3]$

myG23_v $=[172400 /(2 *(1+0.3))]$

\# ply thickness in case of isotropic shell

\# use shell thickness and divide by "myLayerNumber_v"

myLaminateThickness_v $=[0.1 / 8]$

myCore_v $=[12.7]$ 
c. Geometry

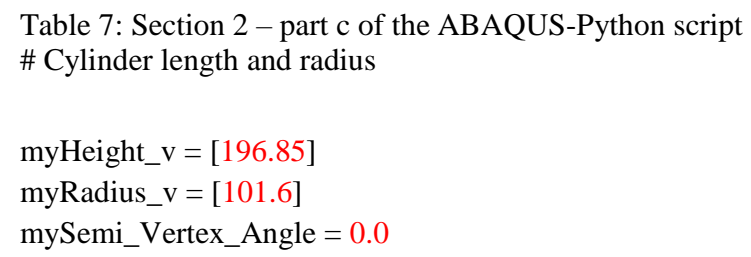

\section{d. Finite Element Analysis}

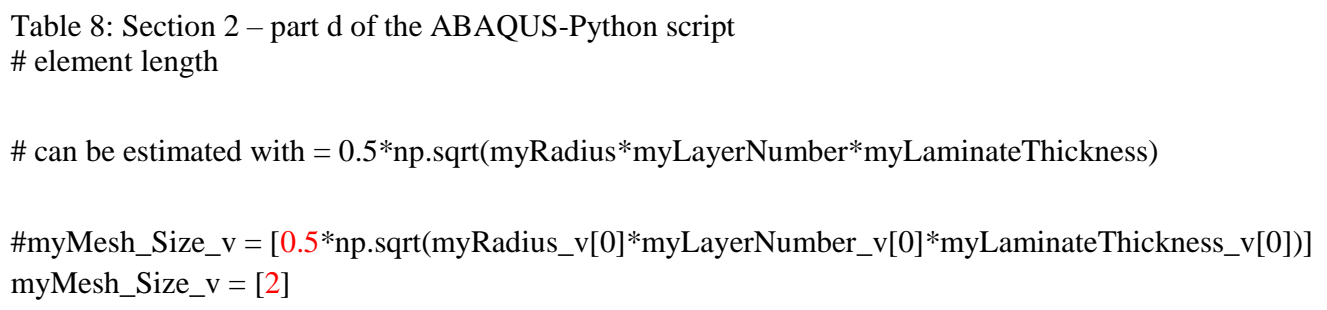

e. LRSM analysis - start \& end iteration, LRSM factor, ABD stiffness

Table 9: Section 2 - part e of the ABAQUS-Python script

\# components of ABD Stiffness matrix

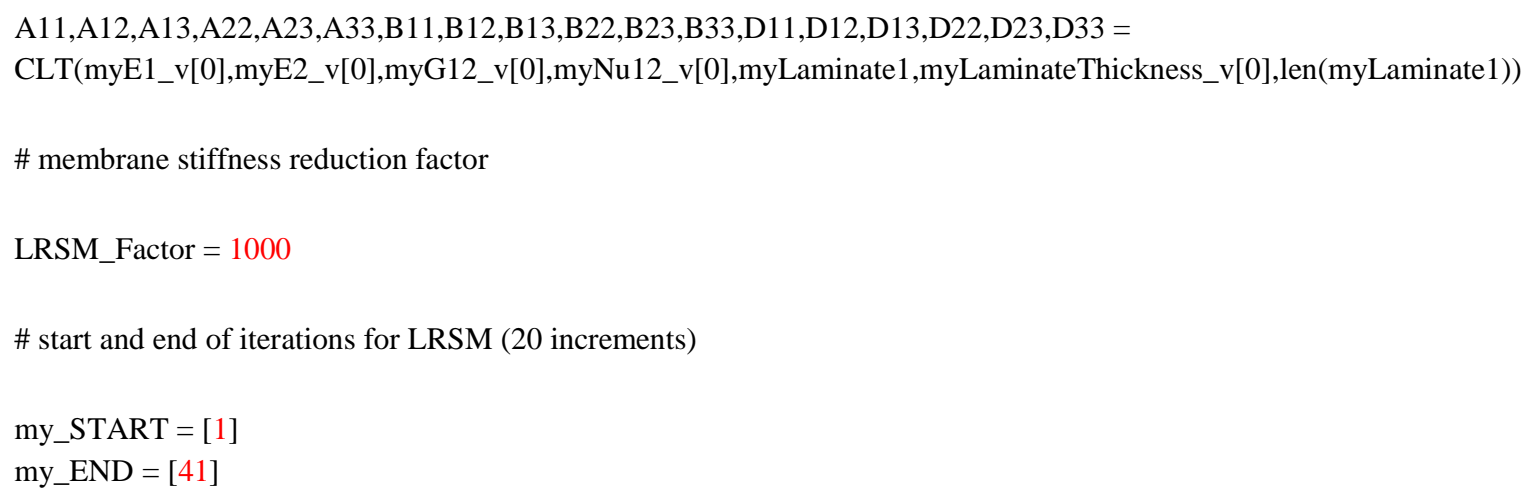

\section{Main Section}

4. Result extraction

The name of the numerical model is defined in the first part (a) of the input section as shown in Table 5.

The material parameter (elasticity modulus, Poisson's ratio, etc.) are defined in the second part (b) of the input section, see Table 6. The isotropic conical shells is represented in this script as a 
composite shells with quasi-isotropic laminate stacking $[45,-45,0,90] \mathrm{s}$. However, this script can also be used to analyze laminated composite shells. The isotropic cylinder has a shell thickness $\mathrm{t}=0.1 \mathrm{~mm}$ which is divided by 8 (number of layers) for the laminate representation. Also, a sandwich core thickness can be defined by using the myCore variable and an angle of $1^{\circ}$ in the variable myLaminate1.

The geometry parameters of the shell are defined in the third part (c) of the input section, see Table 7. This section requires the cylinder radius $\mathrm{R}$, the cylinder height $\mathrm{H}$ and the semi-vertex angle $\beta$. If the semi-vertex angle $\beta=0$, the script will generate a cylinder and for a negative/positive angle a cone will be generated.

The main parameter of the FEA are defined in the fourth part (d) of the input section, see Table 8. The FE mesh can be estimated using $0.5 \sqrt{R \cdot t}$ [95] and the axial displacement (Displacement controlled simulation) can be defined by the user. Another variable is the number of CPUs which depends on the number of available licenses.

The LRSM input data are defined in the fifth part (e) of the input section (see Table 9). In this section a function (CLT) is called which calculates the ABD stiffness matrix components. Also, the membrane stiffness reduction factor is defined as LRSM_Factor (preset to 1000). The final variables are the start and end of the iteration (preset to 40 iterations). Note, that artificial damping can be used by uncommenting line 327 of the function createStaticStep)

The procedure of a numerical analysis using the ABAQUS-Python script consists of the following steps:

1. Start ABAQUS CAE, see Fig. 22 (left)

2. Open the Python script: - Cone_LRSM_clamped_FC_007.py using a text editor (Spyder), see Fig. 22 (right)

3. Define the input section of the Python script, see Table 5 - Table 9

4. Copy whole Python script (CRTL + A), see Fig. 23 (right)

5. Paste the Python script into ABAQUS CAE console (CRTL $+V \&$ Enter to start script), see Fig. 23 (left)

6. Wait for end of calculation, see Fig. 24 (check that line 924 to 928 are uncommented)

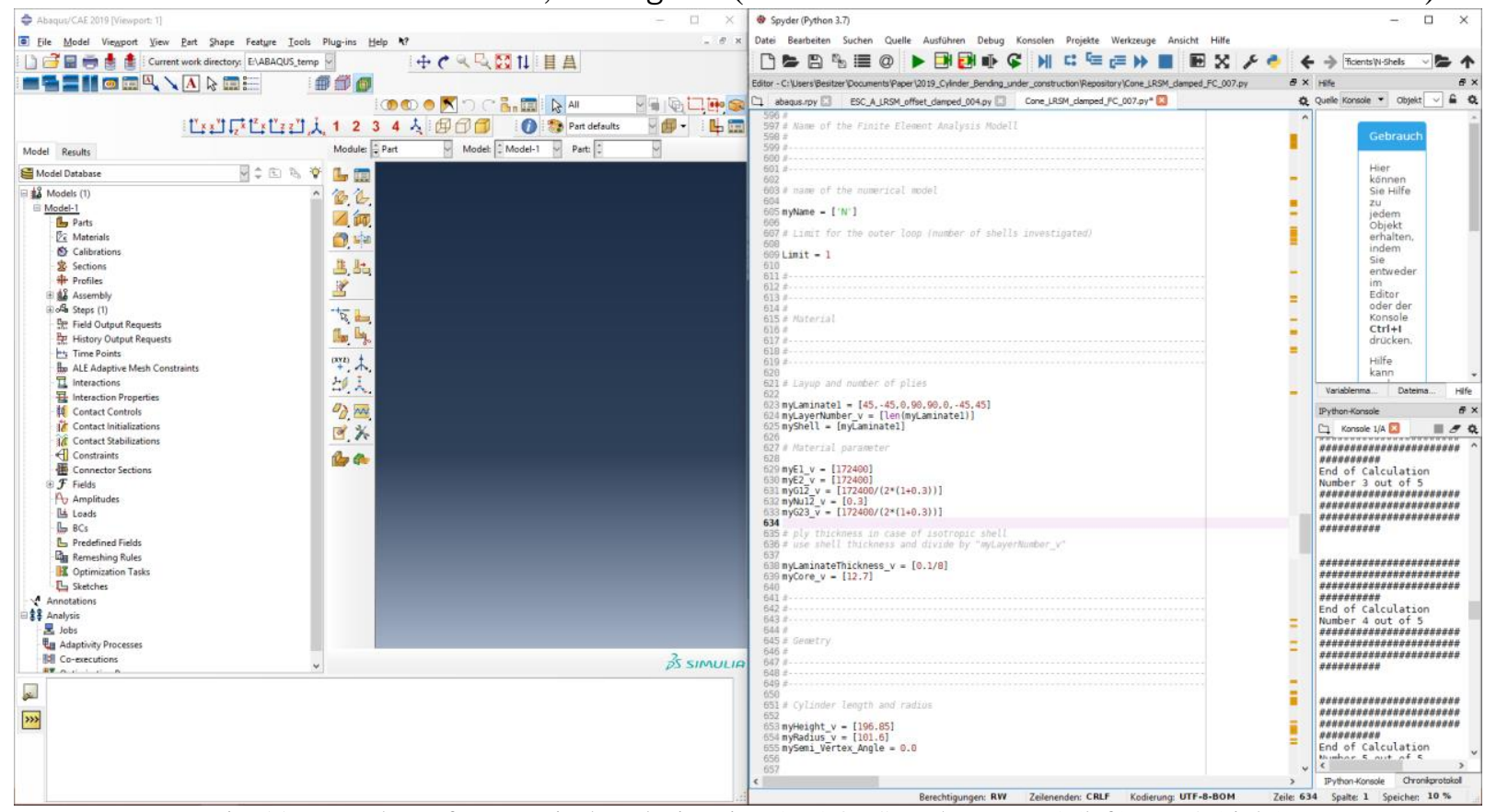

Fig. 22: Procedure of a numerical analysis using ABAQUS-Python: step 1 (left) step 2 (right) 


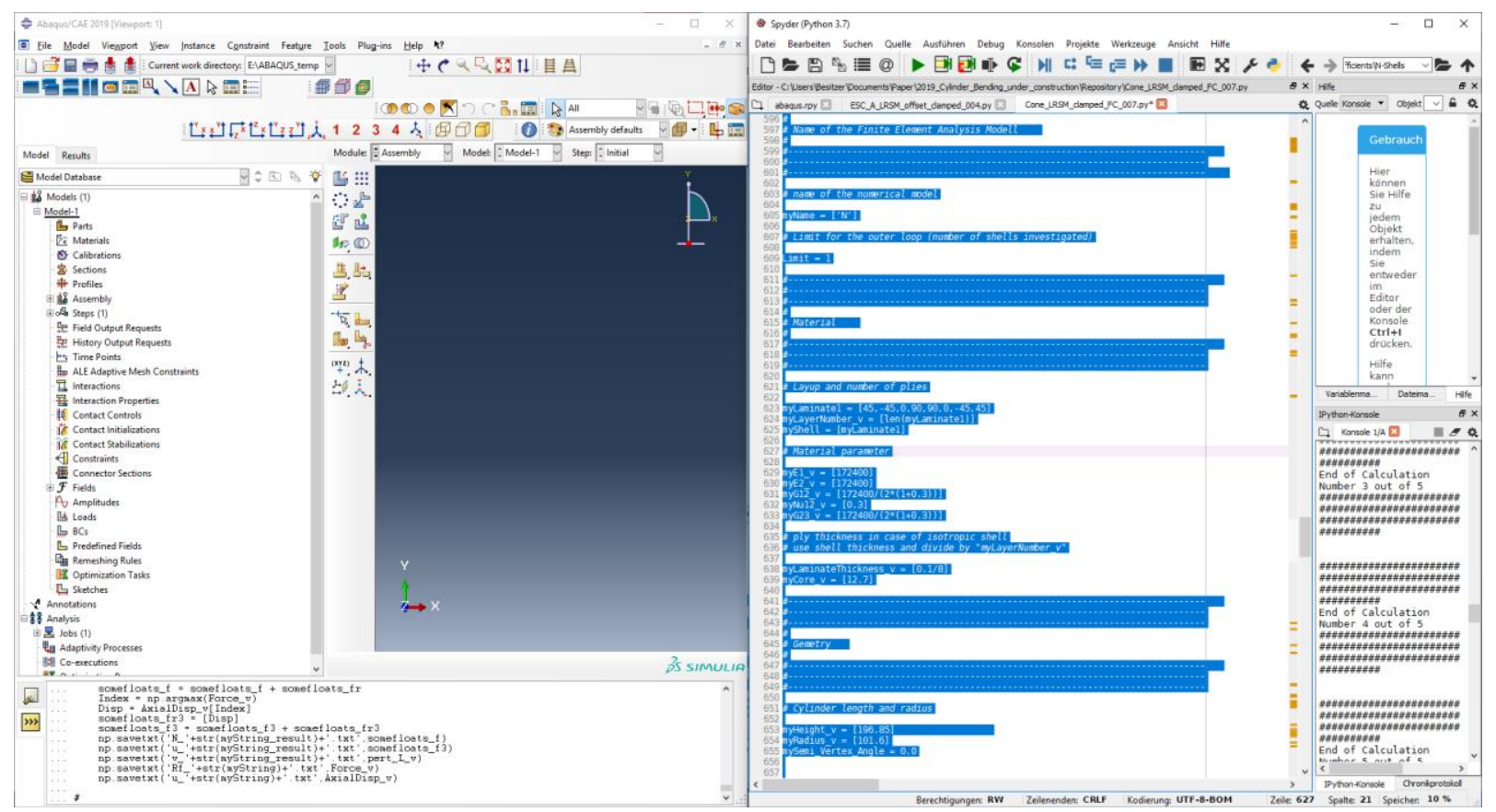

Fig. 23: Procedure of a numerical analysis using ABAQUS-Python: step 4 (left) step 5 (right)

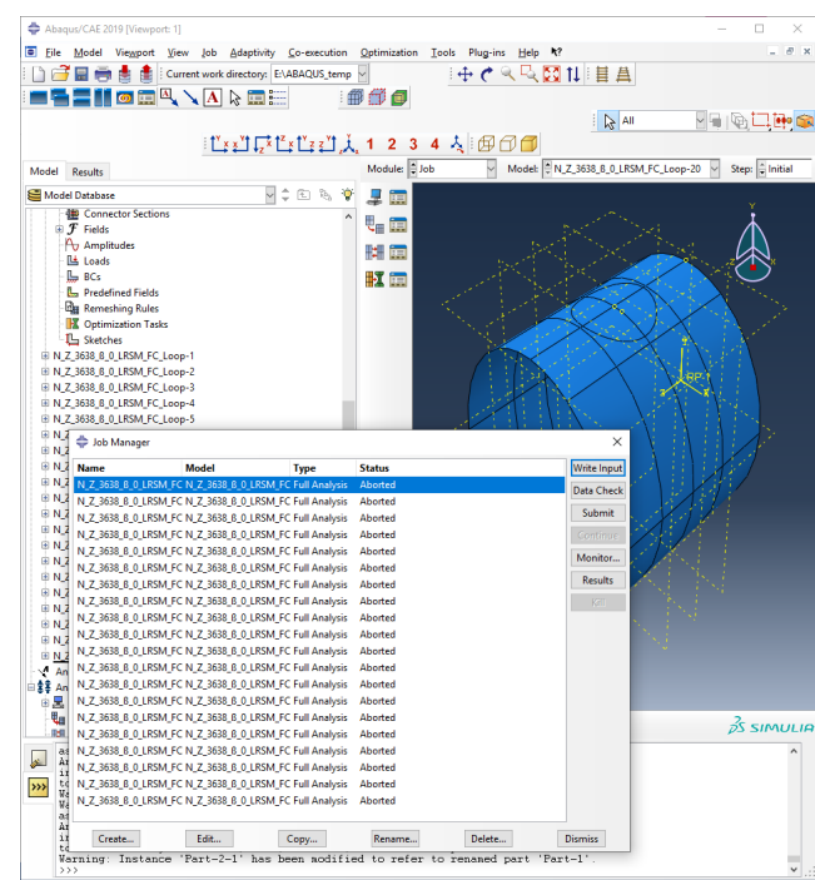

Fig. 24: Procedure of a numerical analysis using ABAQUS-Python: step 6

For the numerical analysis, the Newton-Raphson solution technique was used (Static, General) and the corresponding configurations of the Python script are summarized in Table 10. 
Table 10: Solver settings for ABAQUS

Step

Static,General

\begin{tabular}{lll}
\hline Basic & Incrementation & Other \\
\hline Nlgeom: ON & Type: Automatic & Standard settings \\
Automatic stabilization: None & Increment size: & \\
& Initial: 0.01 & \\
& Minimum: $1 \mathrm{E}-5$ & \\
& Maximum: 0.01 & \\
&
\end{tabular}




\section{Appendix B - Python-Excel script manual}

In this section, a brief overview over the Python-Excel script used in this article is given. This script requires the application of the ABAQUS-Python script from Appendix A and the ABAQUS calculations are finished.

This Python-Excel script writes the data from the ABAQUS calculations in an Excel sheet and determines the lower-bound curve.

The name of the Python-Excel script is:

myPerturbation_Cylinder_READ_005.py

The ABAQUS-Python script has 3 different sections (see Table 11):

1. Section for functions

2. Section for data input:

Table 11: Section 2 - part a of the Python-Excel script

myName $=[$ 'N-Shells_Z_3638_B_0']

\# define axis title

x_axis $=$ ['Axial Displacement [mm]', 'Relative Stiffness S [kN/mm]', 'Relative Strain Energy E [kNmm/kN]']

y_axis = ['Axial Force F [kN]','Axial Force F [kN]','Axial Force F [kN]', 'Buckling Load N [kN]']

max_load $=[$ 'Numerical Collapse Load $[\mathrm{kN}]$ ']

\# method which is evaluated

method $=[$ 'LRSM']

\# axis of perturbation approach

pert_axis $=$ ['LRSM radius-to-shell radius ratio, Rs/R']

\# limits for the perturbation iteration

Pert_START $=1$

Pert_END $=41$

3. Main section

The procedure of the result evaluation using the Python-Excel script consists of the following steps:

1. Open the Python script: - myPerturbation_Cylinder_READ_005.py using a text editor (Spyder), see Fig. 25 (left)

2. Save the Python script: - myPerturbation_Cylinder_READ_005.py in the same folder as the ABAQUS results, see Fig. 25 (right)

3. Run the Python script: - myPerturbation_Cylinder_READ_005.py in Spyder, see Fig. 26 (left)

4. Open Excel result file: - Design_N_Z_3638_B_0_003.xlsx, see Fig. 26 (right)

5. Open Excl sheet: LRSM, see Fig. 27 


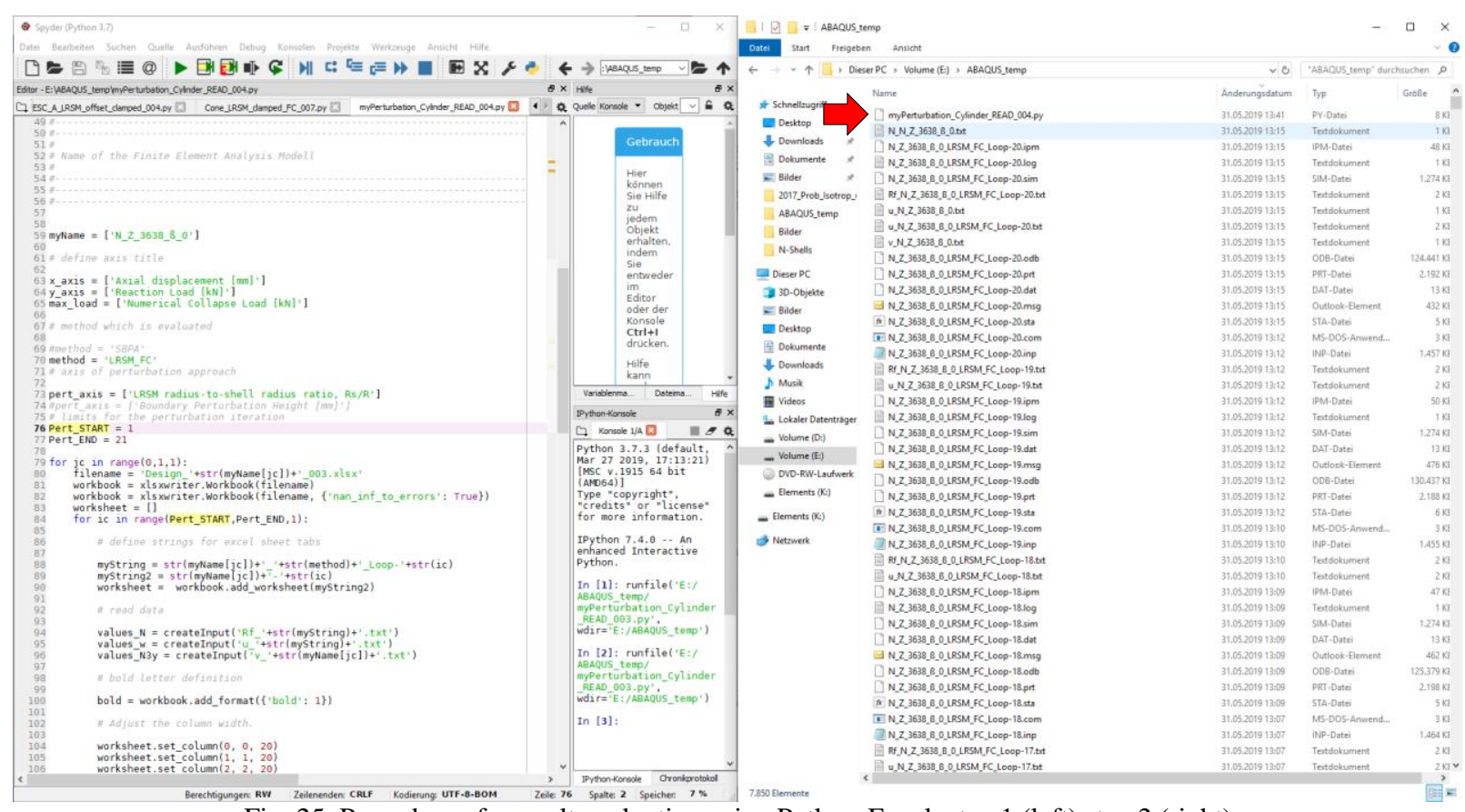

Fig. 25: Procedure of a result evaluation using Python-Excel: step 1 (left) step 2 (right)

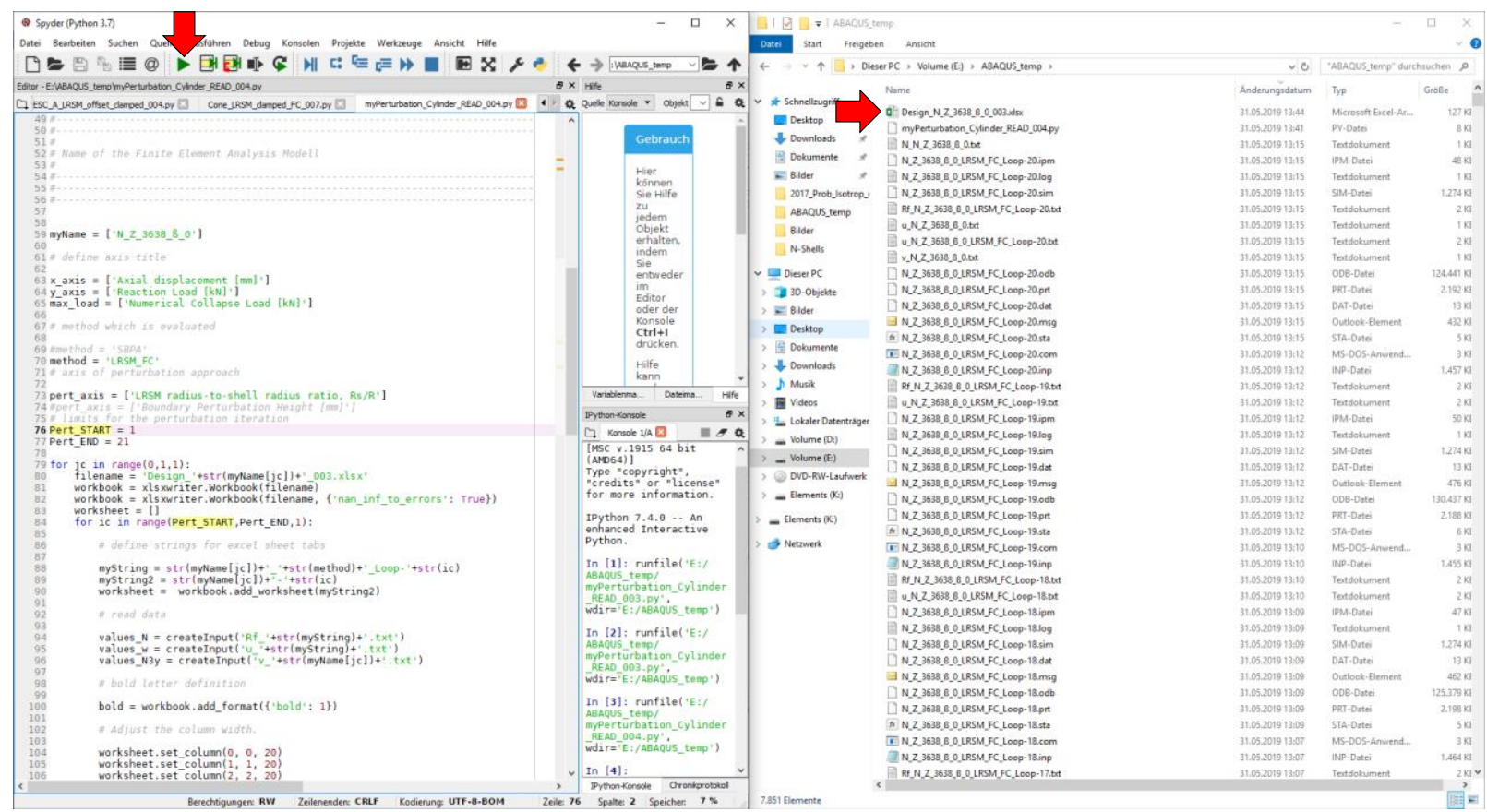

Fig. 26: Procedure of a result evaluation using Python-Excel: step 3 (left) step 4 (right) 


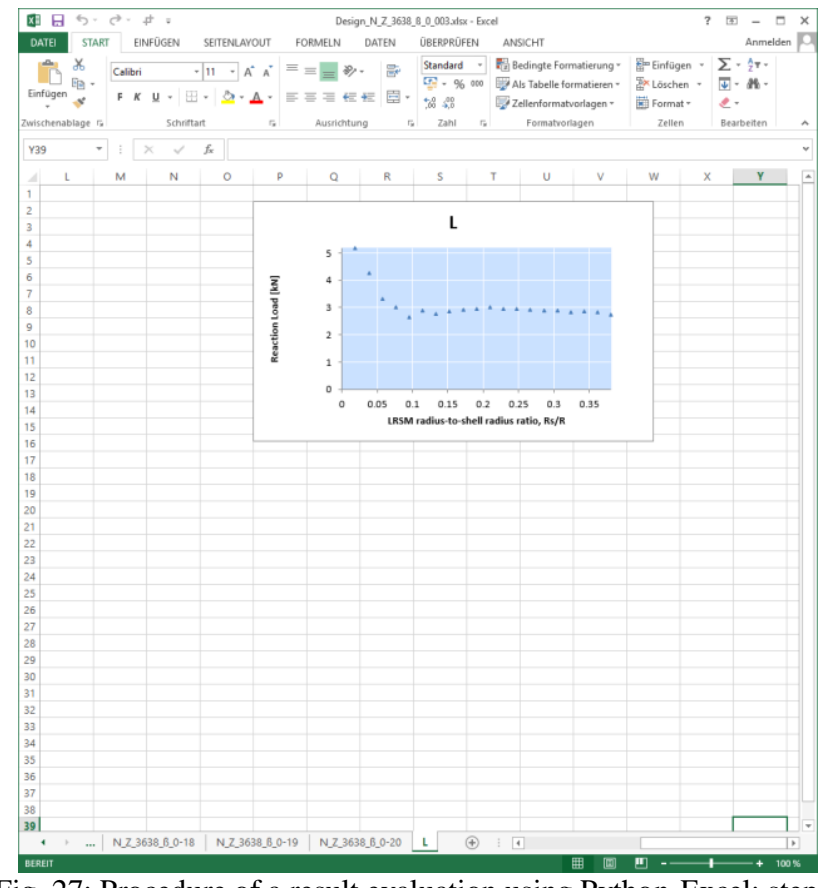

Fig. 27: Procedure of a result evaluation using Python-Excel: step 5 


\section{References}

[1] Rotter, J.M. and H. Schmidt, "Buckling of Steel Shells - European Design Recommendations, 5th Edition, Revised Second Impression," 2013.

[2] B. Almroth, "Influence of imperfections and edge restraint on the buckling of axially compressed cylinders. Technical report, Lockheed Missiles and Space Company, 1966".

[3] C. Babcock and E. E. Sechler, "The effect of initial imperfections on the buckling stress of cylindrical shells. Technical Report NASA TN D-2005, California Institute of Technology, 1963".

[4] J. Arbocz, "The effect of general imperfections on the buckling of cylindrical shells, PhD thesis, California Institute of Technology, Pasadena, California, USA, 1968".

[5] M. Eßlinger and B. Geier, "Gerechnete Nachbeullasten als untere Grenze der experimentellen axialen Beullasten von Kreiszylindern, Der Stahlbau 41, 353-360, 1972".

[6] W. Flügge, "Die Stabilität der Kreiszylinderschale. Ingenieur-Archiv 3, 463-506, 1932".

[7] J. Hutchinson, R. Tennyson and D. Muggeridge, "Effect of a local axisymmetric imperfection on the buckling behavior of a circular cylindrical shell under axial compression, AIAA J. 9, 48-52. (doi:10.2514/3.6123), 1971".

[8] R. Tennyson, "Buckling modes of circular cylindrical shells under axial compression, AIAA J. 7, 1481-1487. (doi:10.2514/3.5419),1969".

[9] R. Tennyson and D. Muggeridge, "Buckling of axisymmetric imperfect circular cylindrical shells under axial compression. AIAA J. 7, 2127-2131. (doi:10.2514/3.5419), 1969".

[10] V. I. Weingarten, E. J. Morgan and P. Seide, "Elastic stability of thin-walled cylindrical and conical shells under axial compression," AIAA Journal, vol. 3, pp. 500-505, 1965.

[11] W. Verduyn and I. Elishakoff, A testing machine for statiscial analysis of small imperfect shells: Part 1. Delft, Netherlands: Delft University of Technology, Department of Aerospace Engineering, 1982.

[12] B. Wang, S. Zhu, P. Hao, X. Bi, K. Du, B. Chen, X. Ma and Y. Chao, "Buckling of Quasi-Perfect Cylindrical Shell under Axial Compression: A Combined Experimental and Numerical Investigation," International Journal of Solids and Structures; In Press, Accepted Manuscript; https://doi.org/10.1016/j.ijsolstr.2017.09.029.

[13] P. Jiao, Z. Chen, X. S. W. Tang and J. Wu, "Design of axially loaded isotropic cylindrical shells using multiple perturbation load approach - Simulation and validation," Thin-Walled Structures, Volume 133, December 2018, Pages 1-16.

[14] H. Schmidt, "Dickwandige Kreiszylinderschalen aus Stahl unter Axialdruckbelastung," Stahlbau, Vol. 58, pp 143-148.

[15] A. Takano, Statistical knockdown factors of buckling anisotropic cylinder under axial compression, vol. 79, Journal of Applied Mechanics (79); http://dx.doi.org/10.1115/1.4006450. 051004-051004, 2012.

[16] E. Labans, H. Abramovich and C. Bisagni, "An experimental vibration-buckling investigation on classical and variable angle tow composite shells under axial compression," Journal of Sound and Vibration, Volume 449, 9 June 2019, Pages 315-329. 
[17] M. Schultz, D. Sleight, N. Gardner, M. Rudd, M. Hilburger, T. Palm and N. Oldfield, "Test and Analysis of a Buckling-Critical Large-Scale Sandwich Composite Cylinder," 2018 AIAA/ASCE/AHS/ASC Structures, Structural Dynamics, and Materials Conference, AIAA SciTech Forum, (AIAA 2018-1693).

[18] F. Franzoni, F. Odermann, E. Lanbans, C. Bisagni, M. Arbelo and R. Degenhardt, "Experimental validation of the vibration correlation technique robustness to predict buckling of unstiffened composite cylindrical shells," Composite Structures, Volume 224, 15 September 2019, 111107.

[19] W. T. Koiter, The Stability of Elastic Equilibrium [PhD thesis] - 1945 [in Dutch], TH Delft, Ed., Englisch Translation NASA TTF-10; 1967, p. 1-833.

[20] M. Hilburger, M. Nemeth and J. J. Starnes, "Shell Buckling Design Criteria Based on Manufacturing Imperfection Signatures," NASA/TM-2004-212659, 2004.

[21] V. Bolotin, "Statistical Aspects in the Theory of Structural Stability".Dynamic Stability of Structures (G. Herrmann, ed.), Oxford: Pergamon Press, 1967, 67-81.

[22] J. Arbocz, "The imperfections data bank, a means to obtain realistic buckling loads," In Ramm E. Buckling of shells, 1982.

[23] J. Arbocz and H. Abramovich, "The initial imperfection data bank at the Delft university of technology part 1," Department of aerospace engineering, LR-290, Delft University of technology, 1979.

[24] J. Arbocz and J. J. Starnes, "Future directions and challenges in shell stability," Thin-Walled Struct, p. 40:729-54, 2002.

[25] J. Kepple, M. Herath, G. Pearce, B. Prusty, R. Thomson and R. Degenhard, "Stochastic analysis of imperfections sensitive unstiffened composite cylinder using realistic imperfections models," Composite Structures, vol. 126, pp. 159-173, 2015.

[26] B. Kriegesmann, R. Rolfes, C. Hühne, J. Teßmer and J. Arbocz, "Probabilistic design of axially compressed composite cylinders with geometric and loading imperfections," International Journal of Structural Stability and Dynamics,, vol. 10, pp. 623-644, 2010.

[27] R. Dancy and D. Jacobs, "The initial imperfection data bank at the Delft University of Technology: Part II.," 1988.

[28] J. H. J. Starnes, M. W. Hilburger and M. P. Nemeth, "The Effects of Initial Imperfections on the Buckling of," Composite Structures - Theory and Practice, P. Grant and C. Q. Rousseau, eds., ASTM STP 1383, pp. 529-550, 2000.

[29] C. Hühne, R. Rolfes, E. Breitbach and J. Teßmer, "Robust design of composite cylindrical shells under axial compression - Simulation and validation," Thin-Walled Structures, vol. 46, p. 947-962, 2008.

[30] R. Degenhardt, A. Bethge, A. Kling, R. Zimmermann and K. Rohwer, "Probabilistic approach for improved buckling knock-down factors of CFRP cylindrical shells," in Proceeding of 18th Engineering Mechanics Division Conference, 2007.

[31] M. Biagi and F. Del Medico, "Reliability-Based Knockdown Factors for Composite," ThinWalled Structures, 46(12), 1351-1358, 2008.

[32] A. Meurer, "Filtering Geometric Imperfection patterns for analysis and design of composite shell structures," Dissertation, Gottfried Wilhelm Leibniz Universität Hannover, 2017, Hannover, Germany: ISD, Institut für Statik und Dynamik. 
[33] V. Bolotin, "Statistical methods in the non-linear theory of elastic shells," Akademii Nauk SSSR, Otdelenie Tekhnicheskykh Nauk 1958;3:33-41 [in Russian; English Translation: NASA TTF-85 1962; 1-16].

[34] I. Elishakoff, "Probabilistic resolution of the twentieth century conundrum in elastic stability," Thin-Walled Structures, vol. 59, pp. 35-57, 2012.

[35] M. S. G. I. Broggi, " Efficient modeling of imperfections for buckling analysis of composite cylindrical shells," Eng Struct ;33:1796-806, 2011.

[36] M. Broggi, A. Calvi and G. I. Schueller, "Reliability assessment of axially compressed composite cylindrical shells with random imperfections," Int J Struct Stab Dyn, 11:215$36,2011$.

[37] C. Schillo, B. Kriegesmann and D. Krause, "Reliability based calibration of safety factors for unstiffened cylindrical composite shells," Composite Structures, Vol.: 168, 798-812, 2017.

[38] I. Elishakoff, S. van Manen and J. Arbocz, "First-order second-moment analysis of the buckling of shells with random imperfections," AlAA Journal, vol. 25, p. 1113-1117, 1987.

[39] B. Kriegesmann, M. Möhle and R. Rolfes, "Sample size dependent probabilistic design of axially compressed cylindrical shells," Thin-Walled Structures, vol. 74, pp. 222-231, 2014.

[40] J. Arbocz and M. W. Hilburger, "Toward a Probabilistic Preliminary Design Criterion," AIAA Journal, 43(8), 1823-1827, 2005.

[41] C. Hühne, R. Zimmermann, R. Rolfes and B. Geier, "SENSITIVITIES TO GEOMETRICAL AND LOADING IMPERFECTIONS ON BUCKLING OF COMPOSITE CYLINDRICAL SHELLS," In Proceedings of European Conference on Spacecraft, 2002.

[42] C. Hühne, R. Zimmermann, R. Rolfes and B. Gier, Loading imperfections - Experiments and computations, Euromech colloquium 424, 2001.

[43] C. Schillo, D. Röstermundt and D. Krause, "Experimental and numerical study on the influence of imperfections on the buckling load of unstiffened CFRP shells," Composite Structures, vol. 131, pp. 128-138, 1 November 2015.

[44] I. Elishakoff, B. Kriegesmann, R. Rolfes, C. Hühne and A. Kling, "Optimization and antioptimization of buckling load for composite cylindrical shells under uncertainties," AIAA Journal, vol. 50(7), pp. 1513-1524, 2012.

[45] R. Khakimova, D. Wilckens, J. Reichardt and R. Degenhardt, "Buckling of axially compressed CFRP truncated cones: Experimental and numerical investigation," Composite Structures, vol. 146, pp. 232-247, 2016.

[46] R. Khakimova, R. Zimmermann, D. Wilckens, K. Rohwer and R. Degenhardt, "Buckling of axially compressed CFRP truncated cones with additional lateral load: Experimental and numerical investigation," Composite Structures, vol. 157, pp. 436-447, 2016.

[47] B. Kriegesmann, R. Rolfes, C. Hühne and A. Kling, "Fast Probabilistic Design Procedure for Axially Compressed Composite Cylinders," Composite Structures, vol. 93, pp. 3140-3149, 2011.

[48] J. Kepple, "Influence of imperfections on axial buckling load of composite cylindrical shells," In: Hoa SV, Hubert P, editors. The 19th international conference on composite materials; 2013..

[49] J. Kepple, B. Gangadhara Prusty, G. Pearce, D. Kelly and R. Thomson, "Improved methods for modeling imperfections for buckling analysis of composite cylindrical shells," ICAS - 
International Council of Aeronautical Sciences (Ed.), 29th congress of the international council of the aeronautical sciences (2014), pp. 2108-2120.

[50] A. Meurer, B. Kriegesmann, M. Dannert and R. Rolfes, "Probabilistic perturbation load approach for designing axially compressed cylindrical shells," Thin-Walled Structures, vol. 107, pp. 648-656, 2016.

[51] M. W. Hilburger, "On the Development of Shell Buckling Knockdown Factors for Stiffened Metallic Launch Vehicle Cylinders," 2018 AIAA/ASCE/AHS/ASC Structures, Structural Dynamics, and Materials Conference.

[52] B. Wang, K. Du, H. Peng, K. Tian, Y. Chai, L. Jiang, S. Xu and X. Zhang, "Experimental validation of cylindrical shells under axial compression for improved knockdown factors," International Journal of Solids and Structures, 2019, accepted manuscript.

[53] H. Wagner, E. Petersen, R. Khakimova and C. Hühne, "Buckling analysis of an imperfectioninsensitive hybrid composite cylinder under axial compression - numerical simulation, destructive and non-destructive experimental testing," Composite Structures, Volume 225, 1 October 2019, 111152.

[54] H. Wagner, C. Hühne and R. Khakimova, "Towards Robust Knockdown Factors For The Design Of Conical Shells Under Axial Compression," International Journal of Mechanical Sciences, Volumes 146-147, October 2018, Pages 60-80.

[55] M. Hilburger, "Developing the next generation shell buckling design factors and technologies," 53rd AIAA/ASME/ASCE/AHS/ASC structures, structural dynamics and materials conference, Honolulu; 2012.

[56] M. W. Hilburger, W. T. Haynie, A. E. Lovejoy, M. G. Roberts, J. P. Norris, W. A. Waters and H. M. Herring, "Subscale and Full-Scale Testing of Buckling-Critical Launch Vehicle Shell Structures," AIAA Paper 2012-1688, NF1676L-13284.

[57] C. Hühne, "Robuster Entwurf beulgefährdeter, unversteifter Kreiszylinderschalen aus Faserverbund," PhD Thesis at Technische Universität Carolo-Wilhelmina zu Braunschweig, 2006.

[58] R. Degenhardt, R. Zimmermann, A. Kling and D. Wilckens, "New Robust Design Guideline for imperfection sensitive composite launcher structures," in 3rd CEAS Congress, Venice, Italy, 2011.

[59] R. Khakimova, C. Warren, R. Zimmerman, S. Castro and R. Degenhardt, "The single perturbation load approach applied to imperfection sensitive conical composite structures," Thin-Walled Structures, vol. 84, pp. 369-377, 2014.

[60] S. G. Castro, R. Zimmermann, M. A. Arbelo, R. Khakimova, M. W. Hilburger and R. Degenhardt, "Geometric imperfections and lower-bound methods used to calculate knockdown factors for axially compressed composite cylindrical shells," Thin-Walled Structures, vol. 74, p. 118-132, 2014.

[61] S. G. Castro, M. A. Arbelo, R. Zimmermann, R. Khakimova and R. Degenhardt, Exploring the constancy of the global buckling load after a critical geometric imperfection level in thinwalled cylindrical shells for less conservative knock-down factors, vol. 72, Int. Journal of Thin-Walled Structures, 2012, p. 76-87.

[62] E. Skukis, O. Ozolins, K. Kalnins and M. Arbelo, "Experimental Test for Estimation of Buckling Load on Unstiffened Cylindrical shells by Vibration Correlation Technique," Procedia Engineering, vol. 172, pp. 1023-1030, 2017. 
[63] E. Skukis, K. Kalnins and O. Ozolins, "Application of Vibration Correlation Technique for Open Hole Cylinders," Nonlinear Dynamics-2016 (ND-KhPI2016) : proceedings of 5th International Conference, dedicated to the 90th anniversary of Academician V. L. Rvachev, pp. 377-383, 2016.

[64] R. Degenhardt, A. Kling, R. Zimmermann and F. Oderman, Dealing with imperfection sensitivity of composite structures prone to buckling, in "Advances in Computational Stability Analysis" ; book edited by Safa Bozkurt Coskun, ISBN 978-953-51-0673-9, 2012.

[65] R. Khakimova, S. Castro, D. R. K. Wilckens and R. Degenhardt, "Buckling of axially compressed CFRP cylinders with and without additional lateral load: Experimental and numerical investigation," Thin-Walled Structures, vol. 119, pp. 178-189, 2017.

[66] H. Abramovich, Stability and Vibrations of Thin Walled Composite Structures, Elsevier Science \& Technology; Woodhead Publishing, 2017.

[67] H. Wagner, C. Hühne, J. Zhang, W. Tang and R. Khakimova, "Geometric imperfection and lower-bound analysis of spherical shells under external pressure," Thin-Walled Structures, Volume 143, October 2019, 106195.

[68] H. Wagner, C. Hühne and S. Niemann, "Robust knockdown factors for the design of spherical shells under external pressure: Development and validation," International Journal of Mechanical Sciences, Volume 141, June 2018, Pages 58-77.

[69] Dassault Systems, ABAQUS 6.13-Software Package, 2013.

[70] J. de Vries, Research on the Yoshimura buckling pattern of small cylindrical thin walled shells, Noordwijk, The Netherlands: Proceedings of the European Conference on Spacecraft Structures, Materials and Mechanical Testing, 2005.

[71] A. Haldar and S. Mahadevan, "Probability, Reliability and Statistical Methods in Engineering Design," 2000.

[72] J. Croll, "Towards simple estimates of shell buckling loads," Der Stahlbau, vol. 1 \& 2, 1975.

[73] E. Sosa, L. Godoy and J. Croll, "Computation of lower-bound elastic buckling loads using general-purpose finite element codes".Computers \& Structures, Volume 84, Issues 29-30, November 2006, Pages 1934-1945.

[74] H. Wagner, E. Sosa, C. Hühne, T. Ludwig and J. Croll, "Robust design of imperfection sensitive thin-walled shells under axial compression, bending or external pressure," International Journal of mechanical sciences, 2019, Vol. 156, 205-220.

[75] H. Wagner, Robust Design of Buckling Critical Thin-Walled Shell Structures, PhD Thesis, Technical University Carolo-Wilhelmina, DLR Forschungsbericht 2019-14, 2018.

[76] T. Ludwig, C. Hühne and L. De Lorenzis, "Rotation-free Bernstein-Bézier elements for thin plates and shells - development and validation," Computer Methods in Applied Mechanics and Engineering, 2019, accepted manuscript.

[77] H. Wagner, H. Koeke, S. Dähne, C. Hühne and R. Khakimova, "Decision tree-based machine learning to optimize the laminate stacking of composite cylinders for maximum buckling load and minimum imperfection sensitivity," Composite Structures, Volume 220, 15 July 2019, Pages 45-63.

[78] J. P. Peterson, P. Seide and V. I. Weingarten, "Buckling of thin-walled circular cylinders NASA SP-8007," Technical Report, 1 Aug 1968. 
[79] H. Wagner, Hühne, S. Niemann and R. Khakimova, "Robust design criterion for axially loaded cylindrical shells - Simulation and Validation," Thin-Walled Structures; http://dx.doi.org/10.1016/j.tws.2016.12.017, vol. 115, pp. 154-162, 2017.

[80] H. Wagner, C. Hühne and S. Niemann, "Robust knockdown factors for the design of axially loaded cylindrical and conical composite shells - Development and Validation," Composite Structures, vol. 173, no. 10.1016/j.compstruct.2017.02.031, pp. 281-303, 2017.

[81] H. Wagner and C. Hühne, "Robust knockdown factors for the design of cylindrical shells under axial compression: potentials, practical application and reliability analysis," International Journal of Mechanical Sciences 135, pp. 410-430, 2018.

[82] H. Wagner, C. Hühne, K. Rohwer, S. Niemann and M. Wiedemann, "Stimulating the realistic worst case buckling scenario of axially compressed cylindrical composite shells," Composite Structures, vol. 160, pp. 1095-1104, 2017.

[83] H. Wagner, C. Hühne and S. Niemann, "Constant Single-Buckle Imperfection Principle to determine a lower bound for the buckling load of unstiffened composite cylinders under axial compression," Composite Structures, vol. 139, pp. 120-129, 2016.

[84] H. Wagner, C. Hühne, S. Niemann, K. Tian, B. Wang and P. Hao, "Robust knockdown factors for the design of cylindrical shells under axial compression: Analysis and modeling of stiffened and unstiffened cylinders," Thin-Walled Struct, 127 (June 2018), pp. 629-645.

[85] A. Evkin, "Local Buckling of Cylindrical Shells. Pogorelov's Geometrical Method," Andrianov I., Manevich A., Mikhlin Y., Gendelman O. (eds) Problems of Nonlinear Mechanics and Physics of Materials. Advanced Structured Materials, vol 94. Springer, Cham.

[86] A. Evkin, V. Krasovsky, O. Lykhachova and V. Marchenko, "Local buckling of axially compressed cylindrical shells with different boundary conditions," Thin-Walled Structures, Volume 141, August 2019, Pages 374-388.

[87] R. Groh and A. Pirrera, "On the role of localizations in buckling of axially compressed cylinders, 475, Proc. R. Soc. A, 2019," https://doi.org/10.1098/rspa.2019.0006.

[88] R. Groh and A. Pirrera, "Localised post-buckling states of axially compressed cylinders and their energy barriers," AIAA Scitech 2019 Forum. January.

[89] ECCS, Buckling of steel shells: European design recommendations, 5th ed., 5th Edition: European Convention for Costructional Steelwork, 2008.

[90] J. Rotter, "Cylindrical shells under axial compression".Chapter 2 of the book Buckling of Thin Metal Structures, edited by JG Teng and JM Rotter, Spon, London, pp-42-87.

[91] J. Rotter, "Shell buckling design and assessment and the LBA-MNA methodology".Stahlbau, Vol. 80, No. 11, 2011, pp. 791-803.

[92] J. Rotter, "The elastic-plastic imperfection sensitivity of axially compressed cylinders with weld depressions".Proc. Eurosteel 2008, 3-5 September, Graz, Austria, pp. 1497-1502.

[93] J. Rotter and A. Hussain, "Length effects in the buckling of imperfect axially compressed cylinders".Proc. SDSS 2016, International Colloquium on Stabiltioy and Ductility of Steel Structures, Timisoara, Romania.

[94] J. Rotter, "The new method of reference resistance design of shell structures".Proc. SDSS 2016, International Colloquium on Stabiltiy and Ductility of Steel Structures, Timisoara, Romania. 
[95] L. Wullschleger and H. R. Meyer-Piening, "Buckling of geometrically imperfect cylindrical shells - definition of a buckling load," International Journal of Non-Linear Mechanics, vol. 37, pp. 645-657, 2002. 